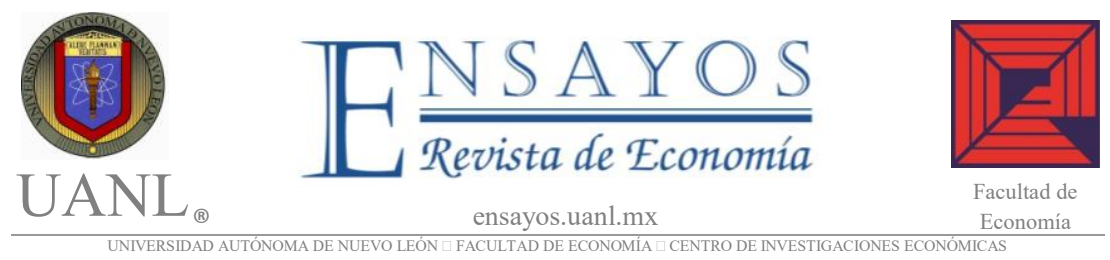

\title{
Análisis regional de sofisticación y centralidad de las exportaciones mexicanas
}

\section{Regional Analysis of Sophistication and Centrality of Mexican Exports}

\section{Sandra Edith Medellín Mendoza Miguel Alejandro Flores Segovia ${ }^{* *}$ Amado Villarreal González}

\begin{tabular}{l}
\hline $\begin{array}{l}\text { Información del } \\
\text { artículo }\end{array}$ \\
\hline Recibido: \\
1 Septiembre 2016 \\
Aceptado: \\
16 Febrero 2017 \\
\hline
\end{tabular}

Clasificación JEL: D85; F11; F14; O18; R58

\section{Palabras clave:}

Exportaciones; Centralidad; Análisis de Redes; Sofisticación; Regional

\section{Resumen}

Se analiza la dinámica exportadora de las actividades industriales en México, mediante la estimación de indicadores regionales de productividad, sofisticación y el análisis de redes para el mapa de espacio de las industrias exportadoras. Los resultados muestran que los productos del sector manufacturero, específicamente la Industria de Equipo de Transporte, tienen un mayor nivel de sofisticación. Además, destacan una mayor conectividad entre industrias, como la región Frontera y Centro-Bajío. Este estudio puede coadyuvar en el diseño de políticas públicas y al desarrollo de cadenas productivas con mayor proximidad en el espacio de industrias.

\footnotetext{
* Investigadora, Instituto de Desarrollo Regional, Escuela de Gobierno y Transformación Pública, Tecnológico de Monterrey. semedellin@itesm.mx.

** Profesor, Escuela de Gobierno y Transformación Pública, Tecnológico de Monterrey. miguelflores@itesm.mx.

**** Profesor, Tecnológico de Monterrey. amado.villarreal@itesm.mx. Ave. Eugenio Garza Lagüera y Rufino Tamayo 66269, San Pedro Garza García. N.L.
} 


\begin{tabular}{|c|c|}
\hline Article information & Abstract \\
\hline $\begin{array}{l}\text { Received } \\
1 \text { September } 2016\end{array}$ & $\begin{array}{l}\text { The export dynamics of industrial activities in the } \\
\text { country is analyzed by estimating regional indicators } \\
\text { of productivity, sophistication and use of network }\end{array}$ \\
\hline $\begin{array}{l}\text { Accepted } \\
16 \text { February } 2017\end{array}$ & $\begin{array}{l}\text { analysis to mp exporting industries space. The } \\
\text { results show that products related to the }\end{array}$ \\
\hline $\begin{array}{l}\text { JEL Classification: } \\
\text { D85; F11; F14; O18; } \\
\text { R58 }\end{array}$ & $\begin{array}{l}\text { manufacturing sector, specifically the Transportation } \\
\text { Industry, have a higher level of sophistication. The } \\
\text { regions with the most connectivity between }\end{array}$ \\
\hline $\begin{array}{l}\text { Keywords: } \\
\text { Exports; Centrality; } \\
\text { Network Analysis; } \\
\text { Sophistication; } \\
\text { Regional }\end{array}$ & $\begin{array}{l}\text { industries are the Border and the Central Bajío. This } \\
\text { study may contribute to the design of public policies, } \\
\text { supporting the development of productive chains } \\
\text { with greater proximity in industry space. }\end{array}$ \\
\hline
\end{tabular}

\section{Introducción}

El sector exportador ha sido uno de los principales motores de crecimiento económico de México a partir de la década de los ochenta, ya que de tener una razón de exportaciones de 8.5\% del PIB en 1960, para 2015 se tiene un indicador exportador del 35.4\% (Banco Mundial, 2017). Ante este crecimiento del comercio exterior, se destaca un rasgo estructural en las diferentes regiones del país, mismo que se distingue por la poca integración doméstica de sus cadenas de valor. Por ejemplo, las regiones Sur y Noroeste, muestran menor capacidad relativa de abasto local, revelando bajos niveles de desarrollo de sus cadenas de proveeduría interregional (Dávila, 2015).

En la localización de industrias con base en las cadenas de valor, se puede distinguir que en la región Norte se tiene la participación más importante del empleo orientado a electrónica, automóviles y prendas de vestir, la región la Capital destaca en la concentración de empleo en química y alimentos procesados (Villarreal, Mack y Flores, 2016).

La percepción internacional también va en el mismo sentido, pues como parte de indicadores de cambio estructural y esfuerzo tecnológico, en 2012 la Comisión Económica para América Latina y el Caribe (conocida por sus siglas en inglés ECLAC) calcula y compara la sofisticación asociada a las exportaciones (EXPY) para varios países, en la cual México destaca entre los valores más altos de exportaciones de alta y media tecnología de Latinoamérica (siendo superior a Brasil y Argentina). Sin embargo, el mismo organismo indica que el cambio estructural en México ha estado limitado por otros factores, como la baja productividad laboral. 
La tendencia que ha existido de este desempeño en la productividad del país, ha sido asociado con el hecho de que el proceso de liberalización comercial llevó a una desarticulación de las cadenas productivas nacionales, posteriores al Tratado de Libre Comercio con América del Norte (TLCAN), siendo ubicados, primordialmente, los procesos de valor y de manufactura en los extremos de la cadena productiva; es decir, en insumos esenciales y en el armado final de los productos, lo cual en parte explica la baja productividad laboral y resalta el hecho de la necesidad de un rescate de las etapas intermedias de las cadenas productivas asociadas a productos y procesos de mayor sofisticación. De acuerdo con Ramírez (2003), el sector exportador maquilador permanece como un sector altamente desarticulado de la economía nacional debido a la limitada proveeduría nacional, ya que en promedio se compra no más del $3 \%$ de componentes, insumos y materiales de los proveedores mexicanos locales.

El desempeño exportador relativo de un país, en términos del volumen y tipo de productos exportados, depende de la ventaja comparativa revelada de los mismos (Balassa, 1965, 1979). Dentro de la variedad de factores que influyen en las exportaciones, resalta el nivel de sofisticación tecnológica, los insumos o productos que intervienen en la cadena de valor, así como la calidad de sus instituciones (Hidalgo, Hwang y Rodrik, 2007). En otras palabras, se habla de un nivel de sofisticación de las exportaciones que depende de las capacidades productivas de la región y, eventualmente, determina la ventaja comparativa de ciertos productos que terminan siendo vendidos al exterior. Recientemente, en la literatura se ha estudiado que una forma de representar la relación de ventaja comparativa, por cada producto y región, es a través del espacio de productos exportados (Hausmann y Klinger, 2006). Por medio de este espacio, es posible ubicar los productos que muestran una similitud o proximidad, a partir de los conocimientos y capacidades requeridas, existentes en los diferentes sectores exportadores de una región.

El objetivo del presente estudio es, en primer lugar, investigar las capacidades exportadoras regionales e identificar sectores industriales que sirven como puentes potenciales de expansión y diversificación industrial. En la medida que las industrias con ventaja comparativa revelada tengan una mayor interactividad con otras industrias, es probable que se obtenga mayor variedad en los tipos de productos que se producen y exportan. Esta proposición se basa en que la riqueza y el desarrollo económico están relacionados con el nivel de complejidad económica, que surge de la interacción entre un número creciente de actividades individuales que integran un sistema económico (Hausmann y Klinger, 2006) ${ }^{1}$.

\footnotetext{
${ }^{1}$ De acuerdo con Hausmann, el término de complejidad económica indica la composición productiva de un país y refleja la estructura que surge para mantener y combinar el conocimiento. La complejidad económica es una medida de sofisticación de las
} 
Aplicando la metodología de Hausmann y Klinger (2006), es posible distinguir qué sectores muestran una mayor proximidad en el espacio de industrias; identificando aquellas industrias que tienen mayor posibilidad de diversificarse con productos cercanos a su estructura exportadora y con capacidad de incorporar productos de mayor sofisticación. Dado que la relación resultante entre industrias se representa mediante una matriz de dimensiones $n x n$, se requiere un análisis formal de esta mediante métodos adecuados. Por tal motivo, como segundo objetivo del estudio se pretende aplicar métodos relacionados con el análisis de redes sociales, los cuales han sido ampliamente utilizados para examinar el perfil de los individuos y su relación con otros individuos, o bien, organizaciones, en estudios de las ciencias sociales para evaluar políticas públicas, o para análisis de tipo cualitativo y cuantitativo, en la misma área (Drew et al., 2011; Fischer, 2011; Boyandi et al., 2012; Bonachev y Buck, 2005).

El análisis de redes permite la identificación de subsectores industriales centrales, que pueden servir de puente o enlace con otras industrias o subsectores.

En resumen, el estudio considera la dinámica exportadora del país mediante el análisis de los niveles de productividad y sofisticación de las actividades industriales. Para esto, se utiliza información desagregada de exportaciones por entidad federativa, a fin de estimar indicadores de productividad, sofisticación y el espacio de subsectores industriales de exportación, durante el periodo de 2007 a 2013. Por lo cual, este estudio contribuye a la literatura existente en tres puntos:

1) Estimación regional de indicadores de sofisticación (EXPY) y productividad de las exportaciones (PRODY).

2) Estimación regional del espacio de subsectores industriales exportadores.

3) Identificación de los subsectores industriales centrales exportadores mediante análisis de red.

Los resultados del estudio muestran que los productos relacionados con el sector manufacturero, específicamente la Industria de equipo de transporte, cuentan con un mayor nivel de sofisticación. Sobresale la mayor conectividad entre industrias de la región Frontera y del Centro-Bajío. Este estudio puede coadyuvar al diseño de políticas públicas, apoyando el desarrollo de cadenas productivas con mayor proximidad en el espacio de industrias, mediante

capacidades productivas de un lugar basado en su diversidad (cuantos diferentes puede producir o exportar) y la ubicuidad (número de regiones que exportan o producen ese producto). 
políticas de promoción a la inversión nacional, apoyo fiscal y mayores créditos a este tipo de empresas.

El resto de este artículo está integrado por: la Sección 1, donde se discute la literatura relacionada con las exportaciones y su proceso de diversificación; la Sección 2, que describe la metodología y los datos que se utilizaron en este estudio; en tanto que la Sección 3, reporta y describe los resultados encontrados; por último, la Sección 5 plantea la discusión final y algunas implicaciones de política pública.

\section{Revisión de la literatura}

En la literatura teórica sobre crecimiento y comercio internacional, hay una corriente que hace énfasis en la diversidad de las capacidades productivas de un país como factor para el crecimiento económico. En específico, se argumenta que entre mayor sea la diversificación de los productos exportados, mayores serán las posibilidades de crecimiento (Herzer y Lehnman, 2006; Cadot et al., 2013, Aditya y Acharyya, 2013). La gama de productos que un país o región produce y exporta está determinado no sólo por factores estructurales como dotaciones de capital físico o humano, trabajo y recursos naturales, junto con la calidad de sus instituciones, sino también por la motivación de los empresarios que asumen los costos de innovación en sectores modernos de la economía (Haussman, Hwang, y Rodrik, 2007; Hernández et al., 2008; Hausmann y Rodrik, 2003).

Haussman et al. (2007), argumentan que además de estos factores estructurales, existen elementos idiosincráticos en estos patrones de especialización comercial, pues señalan que no todos los productos son iguales en términos de las consecuencias del desempeño económico. Esto es, especializarse en algunos productos, como manufacturas con alto contenido de capital humano y de nivel tecnológico elevado, hará que los países crezcan más rápido, mientras que los países que se especializan en productos intensivos en trabajo no calificado y poca intensidad tecnológica, llevarán un lento crecimiento económico.

La idea en el comercio internacional de que la diversificación o especialización de las exportaciones juega un papel determinante en el crecimiento económico de los países, ha sido abordada ampliamente en la literatura (Haussman y Kilinger 2008; Santos-Paulino, 2011). También, se han examinado la diversificación y la complejidad económica en el nivel subnacional, para relacionarlas con el desempeño económico regional (Chávez et al., 2015; Naude et al., 2010). 
Sobre la relación entre crecimiento económico y sofisticación de exportaciones (EXPY), Santos-Paulino (2011) encuentra que EXPY tiene una relación positiva con el crecimiento del PIB per cápita en países como Brasil, China, India y Sudáfrica. Este estudio de corte transversal indica que el hecho de que los países presenten patrones de especialización en el comercio y tengan canastas exportadoras más sofisticadas, incrementa el crecimiento económico. En un estudio para Chile, Herzer y Lehnman (2006) analizan la hipótesis de que la diversificación de las exportaciones y el crecimiento económico están relacionados vía externalidades de learning by doing y learning by exporting. Entre sus hallazgos, encuentran que para el caso chileno, las exportaciones se basan en sectores relacionados con los recursos naturales, como los sectores de minería y agricultura, los cuales juegan una participación importante en el crecimiento económico de los países en desarrollo.

Por otro lado, en Cadot, Carrere y Strauss-Khan (2013), se hace una comparación de los estudios donde la diversificación en exportaciones puede estar conectada con el desarrollo y crecimiento económico, tomando en cuenta también la productividad de la empresa. Una de sus conclusiones es que los países más pobres están menos diversificados y en la medida que van creciendo, se van diversificando; también señalan que la mayor parte de los estudios de diversificación de exportaciones se han enfocado en qué es lo producido y no tanto en cómo es producido.

Destacando la relación de la diversificación de exportaciones y el crecimiento económico en el nivel subnacional, Naudé, Bosker y Matthee(2010) analizan las exportaciones de 354 distritos en Sudáfrica entre 1996 y 2001, siendo de los pocos estudios donde se investiga si los patrones de comercio y sus efectos económicos en el nivel de los países, tienen alguna similitud con los patrones de comercio en el nivel subnacional. Estos autores no encuentran evidencia de que la diversificación en exportaciones de nivel subnacional sea una mejor estrategia para el desarrollo económico. De hecho, se encuentra que los distritos que tuvieron un mayor crecimiento económico en ese lapso, fueron los que se especializaron en exportaciones, sobre todo en productos relacionados con la agricultura y la minería.

Para Sudamérica, se realizó un diagnóstico del crecimiento para Perú y sus principales determinantes (Haussman y Klinger, 2008), en el cual se establece un mapa de espacio de productos para varios años, y se concluye que este país ha tenido oportunidades limitadas de una transformación estructural de su economía, en parte, por la orientación de sus exportaciones en estos años, que ha estado especializada en productos periféricos (alimentos, hidrocarburos, ropa, materias primas). 
En el caso de México, hay pocos estudios que examinen los niveles de sofisticación, o bien, complejidad de las actividades exportadoras. Entre los pocos, se encuentra Chávez et al., 2015, donde se establece la relación directa entre el crecimiento económico y la complejidad económica. El estudio se realiza en el nivel estatal y se reporta evidencia de una relación positiva entre complejidad económica y crecimiento económico, además de identificar un claro patrón regional donde los estados de la frontera son más complejos y los que están en la región centro tienen un nivel intermedio, mientras que los estados de la región sur presentan un bajo nivel de complejidad económica. Los autores indican que una característica de estas economías de baja complejidad económica, es que una buena parte del empleo se dedica a actividades de baja complejidad, como comercio al menudeo, por ejemplo.

\section{Datos y metodología}

\subsection{Estimación de productividad y sofisticación de exportaciones}

En primer lugar, se construye la medida de productividad tomando el promedio ponderado del ingreso per cápita de los países exportadores de un producto, en el cual, las ponderaciones reflejan la ventaja comparativa revelada de cada país en ese producto. De manera que, para cada bien, se genera un nivel asociado de productividad denominado PRODY. Posteriormente, se construye un nivel de sofisticación asociado a la canasta de exportaciones del país EXPY, el cual se calcula con el promedio ponderado de las exportaciones del PRODY para ese país. Se presume que existe una relación positiva entre los niveles de EXPY y el crecimiento económico regional; destaca la región Frontera, como se puede observar en la siguiente tabla de correlaciones:

Tabla 1

Correlación entre sofisticación de exportaciones (EXPY) y el crecimiento económico

\begin{tabular}{lcc}
\hline Regiones & Crecimiento económico* & PIB per capita dls* \\
\hline Total del país & 0.006 & 0.208 \\
Región frontera & 0.365 & 0.835 \\
Región centro bajío & 0.038 & -0.021 \\
Región Sur & 0.641 & -0.439 \\
Región centro capital & -0.685 & 0.163 \\
Resto del país & 0.892 & 0.357 \\
\hline
\end{tabular}

Fuente: Elaboración propia. *Se refiere al crecimiento acumulado de la sofisticación de las exportaciones, del crecimiento económico y del PIB per cápita de 2007 a 2013 
Asimismo, la relación entre los niveles promedio del EXPY e ingreso per cápita entre 2007 y 2013, es positiva y concentrada en las regiones de la Frontera, Centro Bajío y Centro Capital (figura 1).

Figura 1

\section{Relación entre sofisticación de exportaciones e ingreso per cápita promedio anual (2007-2013)}

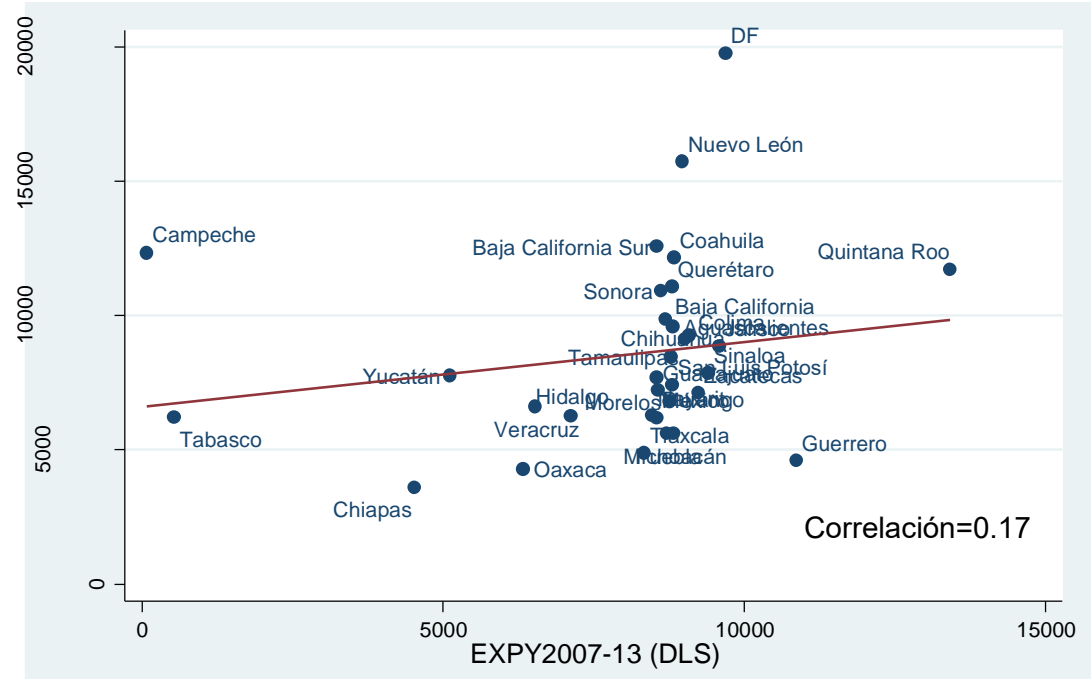

Fuente: Elaboración propia.

Se estima, además, una medida de la sofisticación de las exportaciones (EXPY) a partir del marco conceptual desarrollado en Hausmann, Hwang y Rodrik (2007). Este índice tiene como objetivo capturar el nivel de productividad asociado con la exportación de un país, y se considera como proxy de la canasta de bienes más productivos que un país puede manufacturar en un momento dado. La elección de las exportaciones como proxy, está guiada por la idea de que revelan la frontera de producción, dado que se podría esperar que los países exporten aquellos artículos en los que son más productivos (Anand et al., 2012).

Bajo este marco conceptual, el presente estudio estima un indicador de sofisticación de las exportaciones estatales. Para ello, se inicia con la generación de la variable $P R O D Y$, que es un promedio ponderado del ingreso per cápita de las entidades federativas exportadoras, relacionados con una determinada industria. Este índice cuantitativo ordena los productos comercializados en términos de su productividad asociada, basado en su Ventaja Comparativa Revelada (VCR), dada por: 


$$
\text { VCR } s, p=\frac{\frac{x_{s, p}}{\sum_{p=1}^{n} x_{s, p}}}{\frac{\sum_{s=1}^{32} x_{s, p}}{\sum_{S=1, p=1}^{s 2, p=n} x_{s, p}}}
$$

Donde $s=$ entidad, $p=$ producto (subsector), $x s p=$ exportaciones del producto (subsector) en la entidad $s, Y s=$ producto per cápita de la entidad $s$. Por lo tanto, hay un nivel de $P R O D Y$ para los 22 subsectores, que está dado por:

$\operatorname{PRODY} p=\sum_{s} \operatorname{VCRsp} * Y s$

De esta manera, este indicador (2) representa un promedio ponderado del ingreso per cápita, donde la ponderación corresponde a la ventaja comparativa revelada del estado en esa industria.

Por otro lado, la sofisticación asociada a las exportaciones totales del estado $s, E X P Y_{s}$, está definida a su vez por:

$E X P Y s=\sum_{p} \frac{x_{s, p}}{X_{s}} P R O D Y_{P}$

La ecuación anterior denota que el nivel de EXPY de las exportaciones captura el nivel de ingreso asociado con las exportaciones. Para Haussman et al., (2007), este nivel de ingreso es aproximado al nivel de productividad de las exportaciones $P R O D Y$. Lo importante aquí es la relevancia de $E X P Y$ para medir la productividad asociada con el patrón de especialización del país como una aproximación a la sofisticación de las exportaciones.

Este patrón de especialización también está relacionado con la ventaja comparativa revelada (VCR), en la cual, si este indicador es mayor a 1, indica una especialización del sector exportador en ese bien; si es menor, indica la no especialización. De esta manera, observamos cómo la ventaja comparativa revelada (VCR) determina en gran medida el nivel de productividad de exportaciones para un ingreso per cápita dado, lo que a su vez determina un mayor EXPY por entidad.

Por lo cual, la aparición de varias industrias exportadoras con VCR en una misma región, implica que esta cuente con industrias especializadas en la exportación y que también requieren: factores productivos, capacidad técnica y conocimientos que le permiten obtener una elevada probabilidad de tener ventaja comparativa en dichas industrias. Empíricamente, esta relación entre industrias con VCR y la región, se establece mediante una relación matricial, la cual muestra cómo y dónde una entidad federativa, en nuestro caso, posee VCR mayor a 1 en una determinada industria de exportación, y qué tan cerca se encuentra la misma de otras que no poseen ese nivel de VCR. Analizando 
esta probabilidad conjunta de las industrias, se puede establecer un espacio de industrias exportadoras que representa las formas potenciales para la diversificación de las exportaciones, a partir de la dotación de capacidades y conocimientos prevalecientes. Esto es, una industria exportadora con mayor conectividad que otra, ofrece mayor potencial para la diversificación, mediante las capacidades técnicas y conocimientos compartidos.

Existen estados exportadores, diferentes a las maquiladoras o de productos manufactureros, que han registrado una mayor intensidad exportadora; por ejemplo, está Zacatecas, con vocación minera, Campeche y Tabasco, intensamente petroleros, y Quintana Roo, con mayor capacidad turística, que han desarrollado una capacidad exportadora diferente porque han avanzado en una especialización en estos sectores, lo que les ha permitido la sofisticación de sus exportaciones.

Por ejemplo, la figura 2 muestra el coeficiente de localización para la región sur, dejando fuera el subsector de derivados de petróleo y carbón (324), de 2007 a 2013. En ella, se muestra que las actividades que aumentaron su especialización fueron alimentos (311), así como bebidas y tabaco (312), actividades estrechamente ligadas al sector de turismo.

Figura 2

\section{Región Sur y LQ}

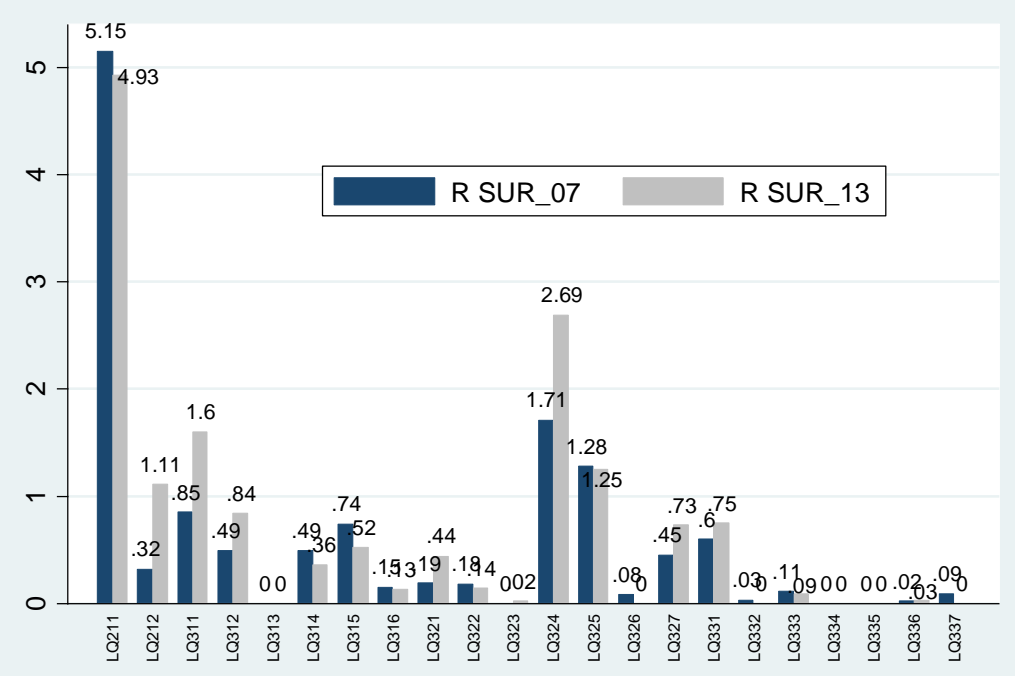

Fuente: Elaboración propia.

Por otro lado, en regiones como centro-bajío se ha dado una mayor especialización, en este periodo de 2007 a 2013, en el subsector de minería 
de carbón mineral (212), seguida de imprenta y conexas (323) y bebidas y tabaco (312) (figura 3).

Figura 3

\section{Región Centro-Bajío y LQ}

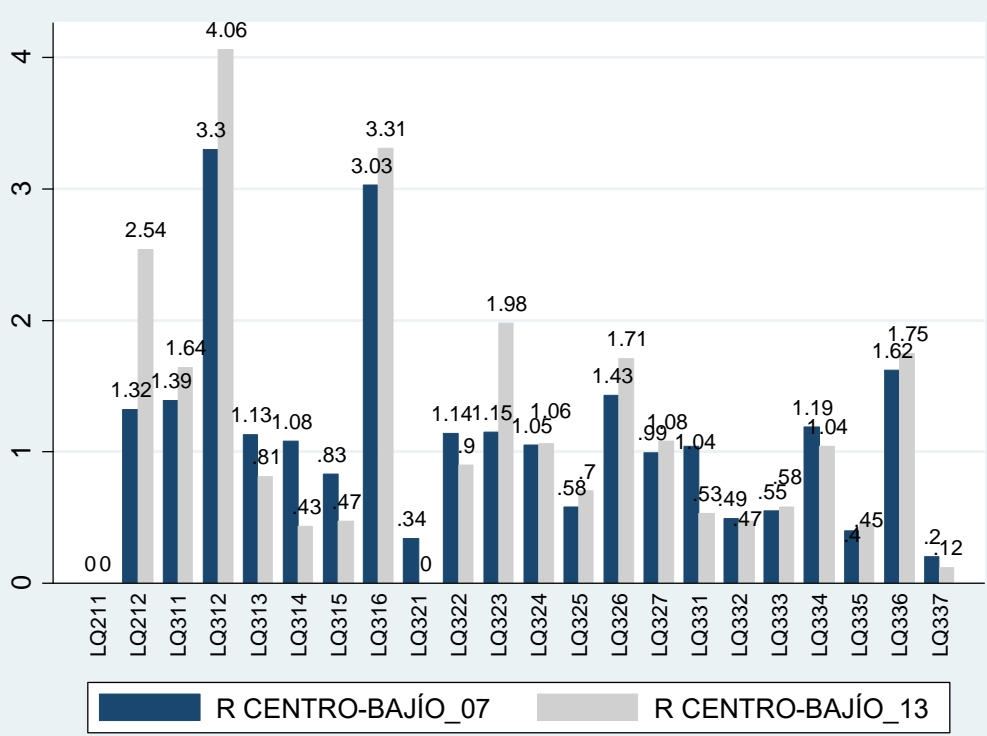

Fuente: Elaboración propia.

En las regiones de Frontera y Centro-Capital, se observa que la especialización de las exportaciones se ha dado en subsectores industriales: equipo de transporte, imprenta y conexas, plástico y hule (figuras 4 y 5).

Actualmente, la discusión de la complejidad (Hidalgo y Hausmann, 2009) se ha dado en torno a que, en este tipo de entidades, se tienen productos exportadores con cadenas de valor ligadas a su vocación productiva regional; los productos, además, tienen características ubicuas, es decir, se ofrecen productos que no se hacen en otros lugares; que además, tienen un grado de diversificación mayor, y con una dotación de recursos relevantes, para generar una mezcla de productos complejos o intensivos en conocimientos. 
Figura 4

\section{Región Frontera y LQ}

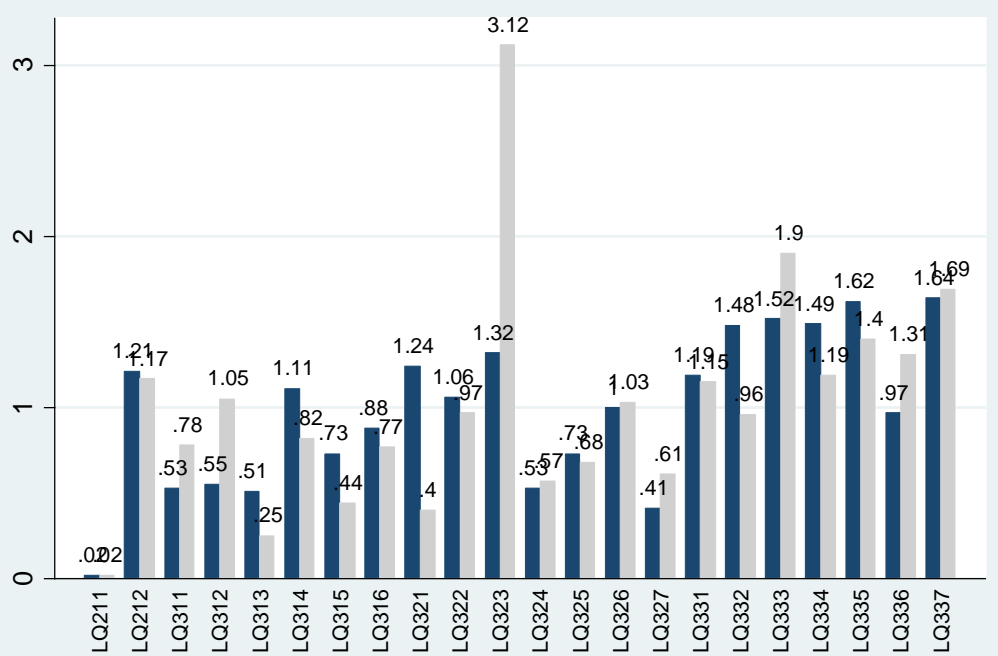

Fuente: Elaboración propia.

R FRONTERA_07

\section{R FRONTERA_13}

Figura 5

Región Centro-capital y LQ

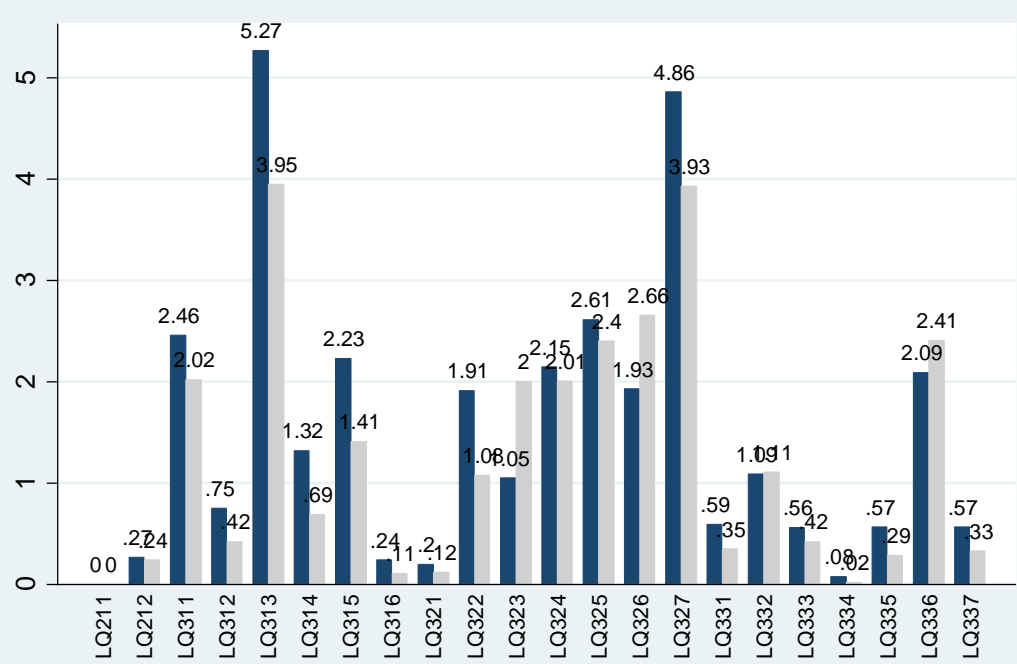

R CENTRO-CAPITAL_07

R CENTRO-CAPITAL_13

Fuente: Elaboración propia. 


\subsection{Métodos para el análisis de redes}

El análisis de red permite indicar de manera gráfica, o bien por medio de un grafo $(\mathrm{G})$, el nivel de intensidad de estas relaciones, donde la conectividad está expresada por nodos $(N)$ y líneas $(L)$. Formalmente, un grafo, $\mathrm{G}(N, L)$, consiste en dos conjuntos de información: un conjunto de nodos, $N=\left\{n_{l}\right.$, $\left.n_{2}, \ldots, n_{g}\right\}$, y un conjunto de conexiones representas por líneas, $L=\left\{l_{l}, l_{2}, \ldots l_{L}\right\}$, entre pares de nodos. Se dice que dos nodos son adyacentes si la línea $l_{k}=\left(n_{i}\right.$, $n_{j}$ ) está incluida en el conjunto de líneas $L$. A su vez, los componentes de la red $(N, L)$ pueden guardar ciertos atributos, por ejemplo, cada elemento en $L$ puede tener un peso específico dentro de la red y ser direccional, es decir, la relación referida va de un nodo a otro y no viceversa; cuando ocurre el caso contrario, se dice que una red es no-direccional.

De la forma como los nodos están conectados entre ellos, subyacen propiedades que a su vez permite el análisis por medio de ciertas métricas. Entre las métricas más usadas se encuentran las relacionadas con la centralidad de la red, de donde es posible comprender cuáles son los nodos o actores de la red que juegan un rol central dentro de la misma (Freeman, 1977, 1979; Newman, 2010). En la literatura de análisis de redes, se han desarrollado numerosas medidas de centralidad, tales como el Grado de Centralización (Degree Centrality), la Centralidad de Cercanía (Closeness Centrality) y la Centralidad de Intermediación (Betweenness Centrality), entre otras más. La utilidad de estas métricas está supeditada a los propósitos del estudio de cada caso analizado, así como a la estructura de los datos ${ }^{2}$.

El presente análisis considera la métrica de Centralidad de Intermediación (Betweenness Centrality) como referencia, al examinar el grado central de una industria dentro de la red de industrias exportadoras. En otras palabras, mayores niveles de centralidad de intermediación caracterizan a industrias "puente", cuya eliminación podría generar una partición de la red, generando una o varias subredes disociadas entre sí (Jason y Zhang, 2013). La idea central es identificar qué industrias se localizan entre otro par de industrias, y que en el agregado, estas sirvan como intermediaras con el resto de las industrias incluidas en la red. La figura 6 muestra en forma gráfica la idea detrás del concepto de centralidad de intermediación.

Formalmente, el concepto de centralidad de intermediación, $C_{k}^{B E T}$, identifica la distancia entre los nodos de una red, también denominada distancia geodésica, y a partir de allí, se calcula el número de caminos geodésicos más cortos de un nodo a otro. Denotemos como $g_{i k j}$ representa el número de caminos más cortos entre $i$ y $j$ que pasan a través de un nodo intermediario $k$,

\footnotetext{
${ }^{2}$ Para una descripción detallada de estas métricas consultar Wasserman y Faust (1994).
} 
de aquí que la $C_{k}^{B E T}$ es la proporción de $k^{\prime} s$ de todos los caminos más cortos de $i$ a $j$, sumada a través de todas las posibles elecciones de $i$ y $j$ :

$$
C_{k}^{B E T}=\sum_{j} \sum_{j} \frac{g_{i k j}}{g_{i j}}
$$

Figura 6

\section{Centralidad de intermediación}

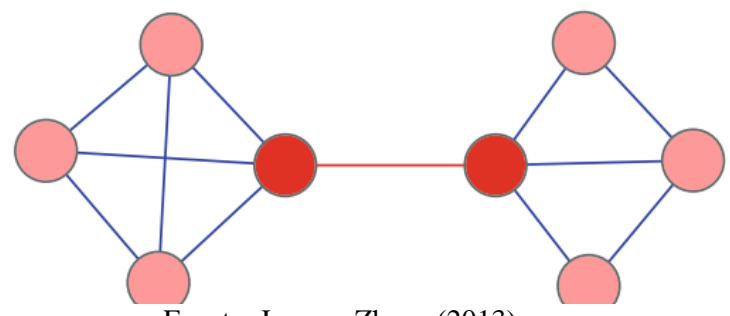

Fuente: Jason y Zhang (2013).

El análisis de red se obtiene mediante la estimación de la conectividad de los 22 subsectores industriales exportadores, anteriormente descritos, donde cada nodo representa un subsector industrial y el vínculo entre estos se obtiene mediante la estimación de la proximidad del espacio de productos, donde a su vez, se establece la relación de cercanía entre productos exportados (Hausmann y Klinger, 2006) ${ }^{3}$. El objetivo central es encontrar la relación entre cada par de subsectores industriales, basados en la probabilidad mínima que tenga cada entidad federativa de exportar en ese par de subsectores.

Esta relación resultante entre subsectores industriales se representa mediante una matriz de dimensiones $22 \times 22$, la cual es analizada con base en una regionalización, dadas las similitudes económicas que los estados presentan. Por ejemplo, de acuerdo con Trejo (2008), el país ha presentado cambios en la geografía económica a partir de la liberalización comercial y del Tratado de Libre Comercio con América del Norte, donde se identifican los estados norteños en la zona fronteriza del país y los del Bajío (Aguascalientes, Querétaro, San Luis Potosí y Guanajuato), como los que reportaron contribuciones significativas para el sector manufacturero, mientras que los estados del Sur, incluyendo Yucatán, registraron una reducción en su contribución al PIB manufacturero. Por su parte, Mendoza y Martínez (1999) detectan un proceso de reorganización sectorial y espacial del empleo en México, identificando una regionalización más dispersa, en el cual el papel de la frontera norte del país ha sido cada vez más sobresaliente, comparado

\footnotetext{
${ }^{3}$ Para una revisión de le metodología consultar Haussman y Klinger, 2006. Structural Transformation y Patterns of Comparative Advantage in the Product Space.
} 
con el sur. Argumentan que esto ha coincidido con la presencia de empresas multinacionales orientadas a las manufacturas de exportación. A su vez, Chávez, Mosqueda y Gómez-Zaldívar (2015) en su análisis sobre la estructura económica, calculan la complejidad económica usando datos de personal ocupado por estado y una clasificación regional, considerando los estados de la frontera norte, los del norte-centro (Aguascalientes, Baja California Sur, Colima, Durango, Jalisco, Michoacán, Nayarit, San Luis Potosí, Sinaloa y Zacatecas) los del centro (Distrito Federal, Estado de México, Guanajuato, Hidalgo, Morelos, Puebla, Querétaro y Tlaxcala) y región sur (Campeche, Chiapas, Guerrero, Oaxaca, Quintana Roo, Tabasco, Veracruz y Yucatán). Estos autores concluyen que hay un claro patrón regional en el cual los estados de la frontera norte son más complejos, comparados con los estados de la región central, mientras que los del sur presentan el más bajo nivel de complejidad.

Para efectos de este análisis, tomando en cuenta los cambios en la distribución geográfica económica, se definieron para la región Frontera, los estados de Baja California, Chihuahua, Sonora, Tamaulipas, Coahuila y Nuevo León; para la región Centro-Bajío, los estados de Aguascalientes, Guanajuato, San Luis Potosí, Querétaro, Zacatecas y Jalisco; para la región Sur, los estados de Tabasco, Campeche, Quintana Roo, Yucatán, Chiapas, Guerrero, Oaxaca, y Veracruz y para la región Centro-Capital, las entidades del Estado de México, el Distrito Federal, Puebla, Tlaxcala, Morelos e Hidalgo.

\subsection{Descripción de datos}

La información utilizada para analizar la productividad y sofisticación de las exportaciones mexicanas por entidad federativa para el periodo 2007 a 2013, se obtiene de las estadísticas del sector externo del Instituto Nacional de Estadística y Geografía (INEGI), que están reportadas en el nivel de sector y subsector de actividad de SCIAN.

Como se mencionó en la sección anterior, hay una relación directa entre la $P R O D Y$ y EXP de las exportaciones, la cual es medida a través de la ventaja comparativa revelada $(V C R)$ de un producto. Entre mayor sea la $V C R$, mayor será la productividad de las exportaciones de esa clase de productos y por consiguiente mayores niveles de sofisticación podrán ser alcanzados. Dada la estructura de la base de datos, es posible estimar valores de $V C R$ a nivel de subsector y por entidad federativa, misma que se establece mediante una relación matricial que muestra cómo y dónde una entidad federativa posee $V C R$ mayor a 1 en determinado subsector de exportación, y qué tan cerca se encuentra ese subsector de otros que no poseen ese nivel de VCR. 
De esta manera, se crea al final una matriz que corresponde al espacio de industrias de exportación que abarca los 22 subsectores industriales por entidad federativa. En términos del espacio de subsectores industriales exportadores, al existir varios con VCR en una misma región, implicaría que la región tiene industrias especializadas que requieren factores productivos, capacidad técnica y conocimientos. Así pues, este espacio de subsectores exportadores representa las formas potenciales para la diversificación de las exportaciones a partir de la dotación de capacidades y conocimientos prevalecientes.

\section{Resultados}

\subsection{Productividad y sofisticación de exportaciones}

Las ventas al exterior (que sólo incluyen minería e industria manufacturera) han presentado un comportamiento heterogéneo en su crecimiento promedio anual del periodo 2007 al 2013 entre las entidades (figura A1 del anexo). Cuando se desagregan las exportaciones por subsector industrial, se encuentra que las relacionadas con actividades manufactureras han sido las que han aportado un mayor dinamismo, destacando ampliamente la participación de las exportaciones en industrias más especializadas, como la Industria de Equipo de Transporte, que aportan 34 por ciento de las ventas totales al exterior, participación que contrasta con el 2 por ciento que representó en 2007 (figura A2 del anexo). Adicionalmente, la Industria de Maquinaria y Equipo, Alimentos, la del Plástico y Hule, del Carbón y Petróleo, Bebidas y Tabaco, de Productos No Metálicos, de Impresión, así como actividades relacionadas con la Minería, han incrementado también su participación en este lapso. Este patrón de exportaciones, donde predominan las manufacturas en mayor medida que las actividades relacionadas con la minería, parece indicar que se ha desarrollado una capacidad exportadora en las diferentes regiones del país, lo que ha permitido cierta sofisticación de sus exportaciones.

Para conocer los niveles de productividad y sofisticación de las exportaciones, se estiman los indicadores, PRODY y EXPY, tal como se describen en la sección anterior. Se encuentra que las industrias relacionadas con productos primarios o de media y baja intensidad tecnológica, como los de las Industrias de derivados del Petróleo y Carbón, de Bebidas y Tabaco, de Madera y de Piel y Cuero, tienden a tener un bajo nivel de PRODY, es decir, bajos niveles de productividad de exportaciones (tabla 2). A excepción de la Extracción de Gas y Petróleo, las industrias relacionadas con el sector moderno o de alta intensidad tecnológica, como la de Impresión y conexas, 
Química y de Fabricación de Aparatos Eléctricos y Equipo de generación de energía, destacan entre las de más alto $P R O D Y$ para el mismo periodo ${ }^{4}$.

Tabla 2

Crecimiento medio anual del PRODY, por subsector 2007-2013

Los subsectores más bajos

324 Industria carbón y petróleo

312 Bebidas y tabaco

321 Fabricación de madera

316 Fabricación de piel y cuero

Los subsectores más altos

211 Extracción de gas y petróleo

323 Industria impresión y conexas

332 Industria productos metálicos

335 Industria aparatos eléctricos, equipo de generación de energía eléctrica 325 Industria Química

Fuente: Elaboración propia.

A partir de la estimación del indicador de PRODY es posible estimar la sofisticación de las exportaciones tanto en el nivel nacional, como para cada una de las entidades federativas. La figura 7 reporta la estimación del crecimiento promedio anual del indicador EXPY por entidad federativa para el periodo de 2007 a 2013. Como se observa, los estados que tienen un nivel de ingreso per cápita estatal por encima del promedio nacional, las entidades de Quintana Roo, Distrito Federal, Coahuila, Querétaro, Sonora y Nuevo León, presentan un mayor crecimiento en el nivel de sofisticación de sus exportaciones. Mientras que las entidades con un ingreso per cápita por debajo del promedio, Guerrero, Sinaloa, Tlaxcala y Estado de México, son estados con el peor desempeño de EXPY.

La figura 8 muestra los niveles de EXPY para la región Frontera. En ella, se muestra que los estados que más han contribuido al dinamismo del EXPY han sido Tamaulipas, Nuevo León, Coahuila y Chihuahua. Para esta región, los sectores que destacan con un mayor nivel de sofisticación de las exportaciones son la Industria de Impresión y conexas, Bebidas y Tabaco, Alimentos, Equipo de Transporte y Productos No Metálicos.

\footnotetext{
${ }^{4}$ La lista completa de los 22 subsectores se puede facilitar, a solicitud expresa con los autores.
} 
Figura 7

Tasa de crecimiento promedio anual de EXPY por entidad (20072013)

$$
-4.0 \% \quad-2.0 \% \quad 0.0 \% \quad 2.0 \% \quad 4.0 \%
$$

Aguascalientes
Baja California
Baja California Sur
Campeche
Chiapas
Chihuahua
Coahuila
Colima
DF
Durango
Guanajuato
Guerrero
Hidalgo
Jalisco
Michoacán
Morelos
México
Nayarit
Nuevo León
Oaxaca
Puebla
Querétaro
QuintanaRoo
San Luis Potosí
Sinaloa
Sonora
Tabasco
Tamaulipas
Tlaxcala
Veracruz
Yucatán
Zacatecas

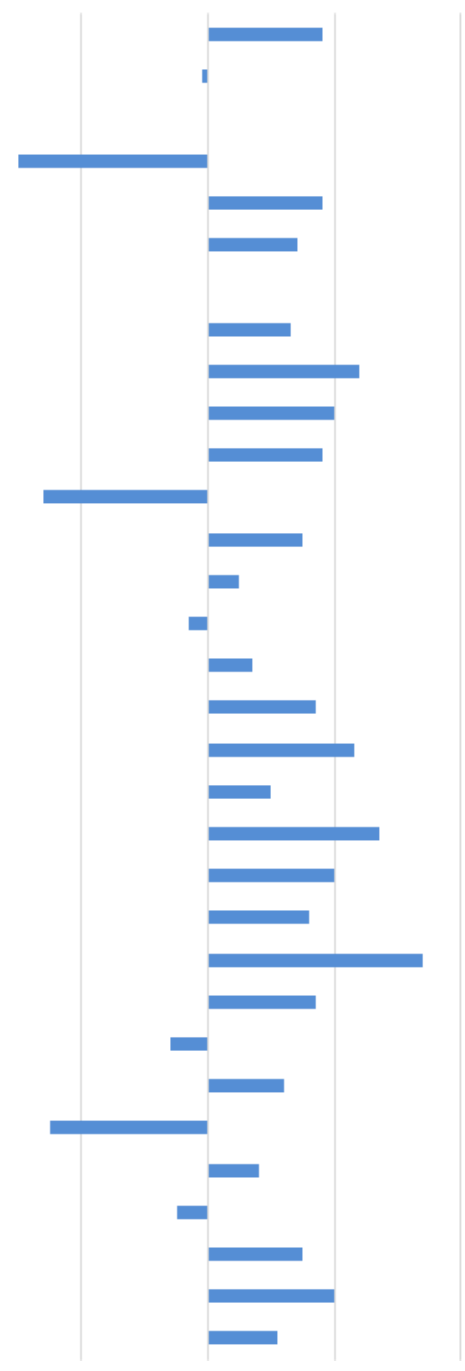

Fuente: Elaboración propia. 
Figura 8

Nivel de EXPY región Frontera

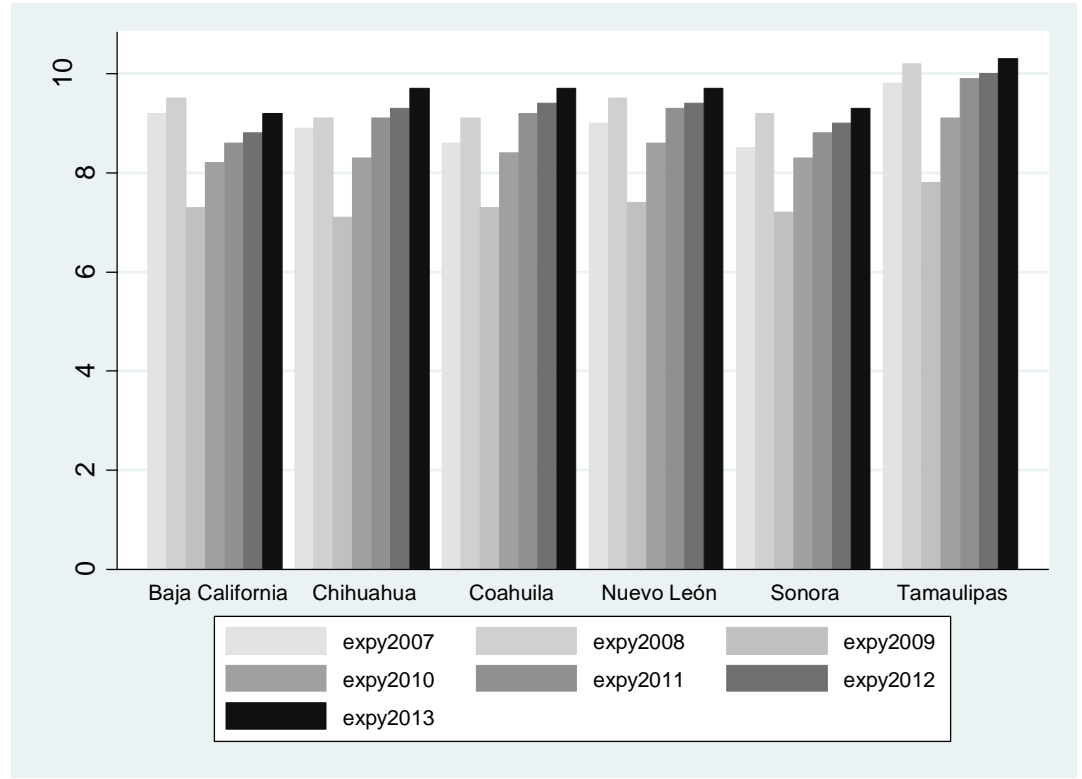

Fuente: Elaboración propia.

En la región Centro-Bajío, como se muestra en la figura 9, los estados con mejor desempeño en esta década han sido: Zacatecas, Aguascalientes, Querétaro, San Luis Potosí. Los sectores de la región Centro-Bajío que más sofisticación de las exportaciones por producto registraron, son los relacionados con Bebidas y Tabaco, Minería de Metálicos y No Metálicos, la industria de Plástico y Hule, de Productos Metálicos, Química y de Alimentos.

En la región Sur (figura 10), el estado con el menor nivel de EXPY fue Yucatán, lo cual sugiere que el nivel de contenido tecnológico ha sido menor en las exportaciones en esta región. Le siguen, con el peor desempeño, estados como Guerrero y Oaxaca. En esta región, los sectores con un mayor crecimiento de EXPY son productos relacionados con sectores tradicionales (de aquí su baja complejidad económica), como Alimentos y Textiles. Entre los sectores con mayor nivel de intensidad tecnológica que destacan con un mayor EXPY, está la Industria de Aparatos Eléctricos, Transporte y Equipo de Cómputo. 
Figura 9

Nivel de EXPY región Centro-Bajío

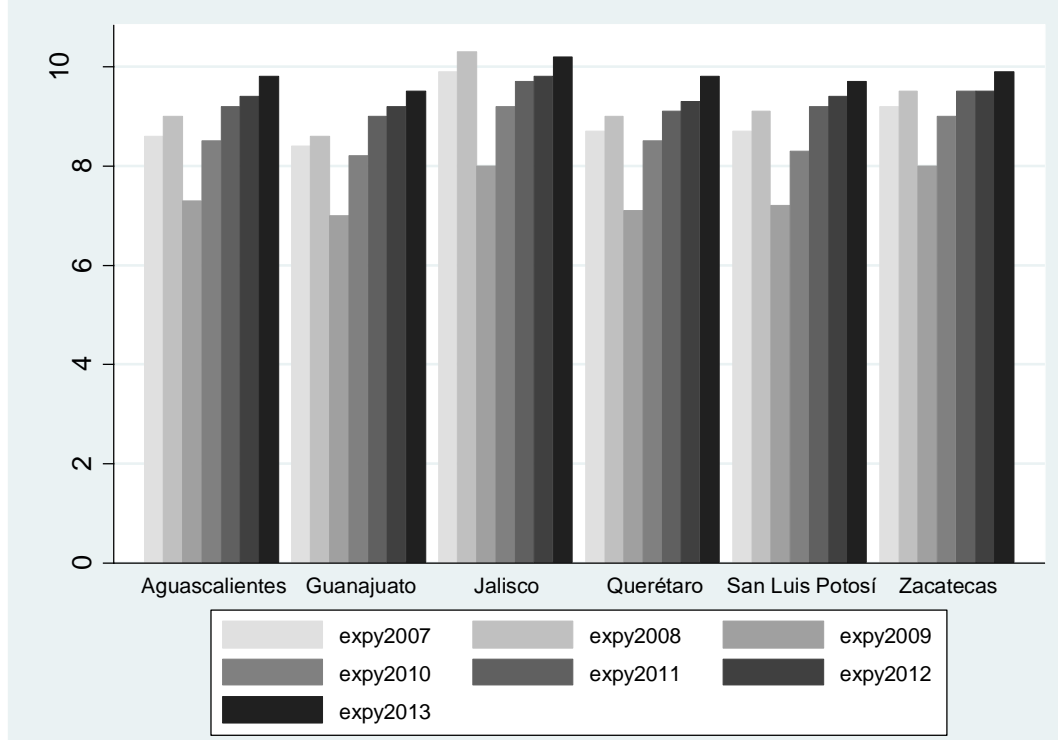

Fuente: Elaboración propia.

Figura 10

Nivel de EXPY región Sur

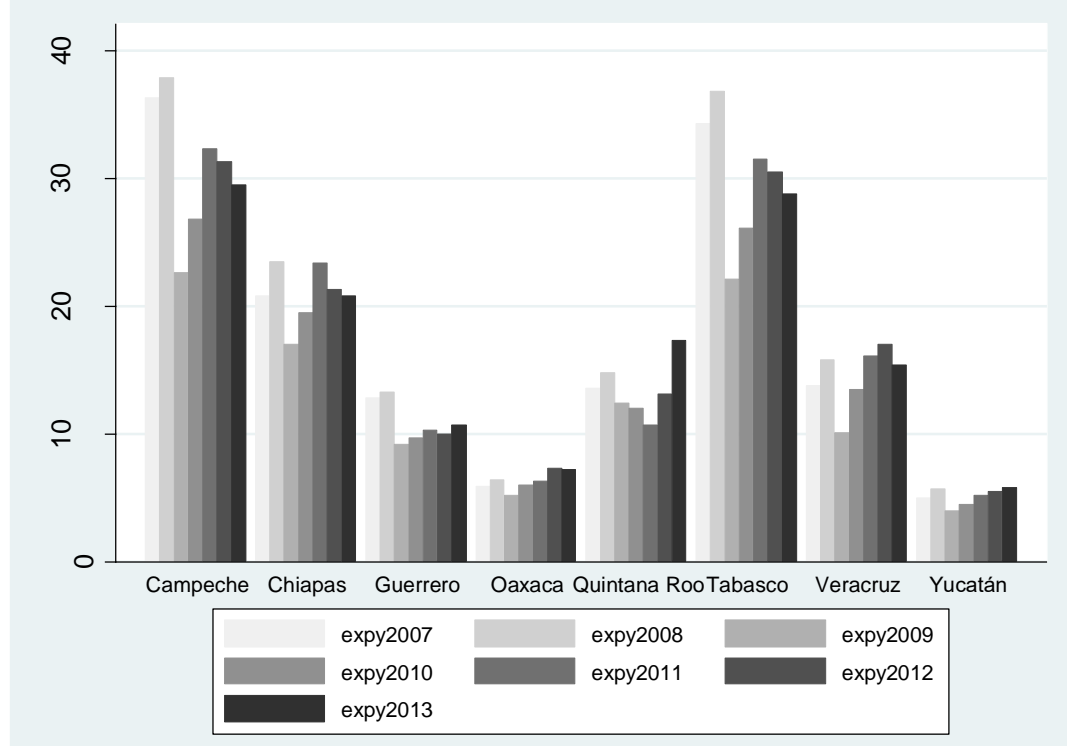

Fuente: Elaboración propia. 
Para la región Centro-Capital (figura 11), la sofisticación de exportaciones ha estado más concentrada y con un mayor dinamismo en Distrito Federal, Puebla y Morelos, sobre todo después de 2009. Este nivel de sofisticación elevado en la región, se encuentra dominado principalmente por productos exportados relacionados con Minería de Metálicos y no Metálicos y la Industria de Plástico y Hule.

Figura 11

\section{Nivel de EXPY región Centro-Capital}

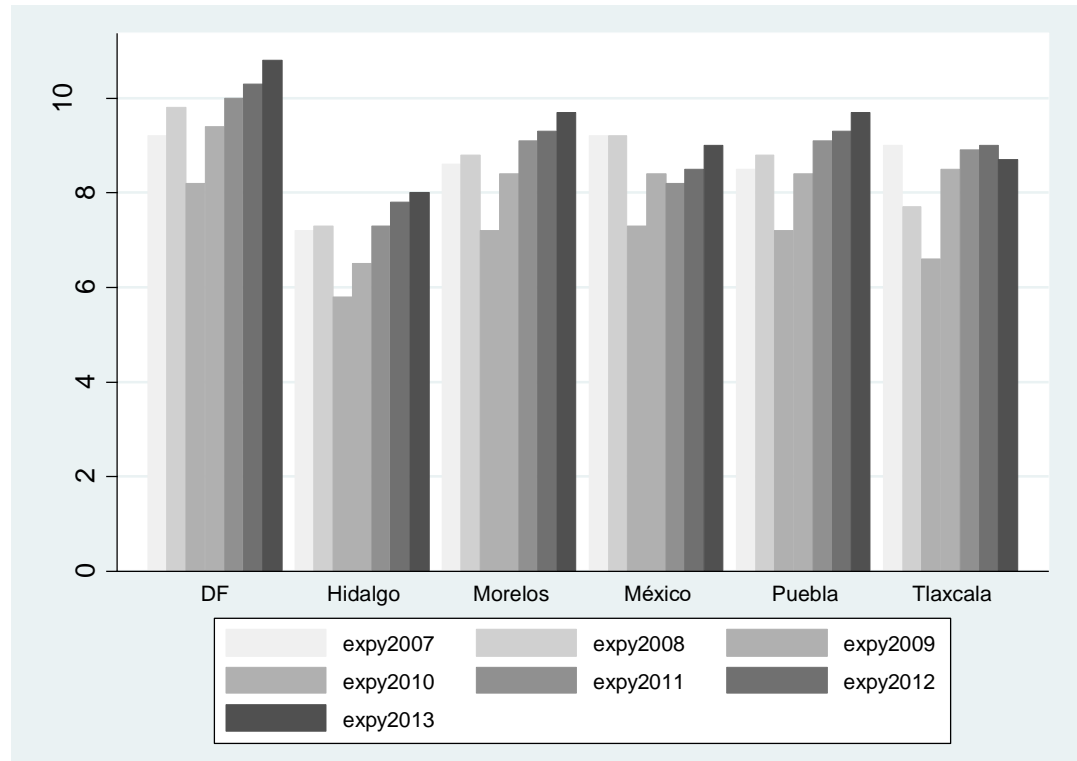

Fuente: Elaboración propia.

\subsection{Proximidad de industrias exportadoras}

Para distinguir la similitud en cuanto a las capacidades, insumos y uso de tecnología en las exportaciones, se estima la proximidad del espacio de subsectores exportadores. Una mayor proximidad sugiere que se tiene mayor posibilidad de diversificarse con productos o industrias cercanos a su estructura exportadora, incorporando productos de mayor sofisticación. Un producto o industria con más enlaces que otros que no se exportan, ofrece mayor potencial para diversificación a través de las capacidades y conocimientos compartidos. Y si, además, estas capacidades y conocimientos son complejos, entonces esta industria tiene un alto potencial de elevar la complejidad económica de la región. De esta manera, lugares altamente complejos tienden a ser más productivos y generar mayores ingresos para su 
población. Para efectos prácticos, se estima la matriz de proximidad de las exportaciones por subsector y entidad federativa en donde se calcula a su vez la distancia (no física) entre cada par de industrias, lo que representa la probabilidad mínima que tienen los estados de exportar en ese par de industrias.

Los resultados obtenidos de esta matriz de proximidad se presentan en la tabla 2. En ella se indica la proximidad que tienen las Industrias de Extracción de Petróleo y Gas, Productos Metálicos y Química con el resto de las industrias. En ella también se muestra, por ejemplo, que entre las industrias exportadoras, la Industria Química es muy cercana a la Industria de Plástico y Hule, pero está muy distante del subsector de Fabricación de Muebles, así como de las Metálicas Básicas. De hecho, tanto el subsector de Productos Metálicos como el de Química tienen más enlaces hacia otras industrias de lo que tiene la industria de Extracción de petróleo y Gas, lo que sugiere que estas dos industrias tienen un alto potencial para impulsar la diversificación exportadora hacia el resto de los subsectores.

Nuestro último conjunto de resultados consiste en visualizar y, consecuentemente, generar un análisis detallado sobre la conectividad nacional y regional de los 22 subsectores exportadores. Como se explicó anteriormente, la estimación de proximidad en el espacio de industrias da pie a una matriz de dimensiones $n x n$, lo que a su vez requiere el uso de técnicas de un análisis de grafos o redes, donde el objetivo central es identificar qué nodo o subsector industrial sirve como "puente" a otros subsectores. Para estos propósitos, se usa el indicador de betweeness centrality; entre mayor sea este indicador implica una mayor importancia para la interactividad del resto de las industrias.

Tabla 3

Lista de proximidad de algunas industrias*

Proximidad de Extracción de Petróleo y gas

Probabilidad

Química

0.27

Bebidas y tabaco

0.13

Productos textiles, excepto ropa

0.13

Alimentos

0.12

Plástico y hule

0.06

Proximidad de Productos metálicos

Probabilidad

Acc. eléctricos y equipo de generación de energía 0.44

Papel

0.44

Plástico y hule

0.38

Insumos y acabados textiles 
Imprenta e industria conexas

0.33

Fab. de muebles, colchones, persianas

0.33

Confección de ropa

0.30

Maquinaria y equipo

0.30

Alimentos

0.29

Minerales no metálicos

0.29

Química

0.27

Equipo de transporte

0.27

Bebidas y tabaco

0.22

Productos textiles, excepto ropa

0.22

Petróleo y carbón

0.22

Metálicas básicas

0.22

Equipo de computación

0.22

Minerales metálicos y no metálicos

0.20

Madera

0.11

\section{Proximidad de Química}

Probabilidad

Plástico y hule

0.44

Insumos y acabados textiles

0.42

Alimentos

0.41

Confección de ropa

0.36

Imprenta e industria conexas

0.36

Equipo de transporte

0.36

Minerales no metálicos

0.29

Extracción petróleo y gas

Papel

0.27

Productos metálicos

Maquinaria y equipo

Acc. eléctricos y equipo de generación de energía

0.27

Bebidas y tabaco

0.18

Productos textiles, excepto ropa

0.18

Petróleo y carbón

0.18

Equipo de Computación

0.18

Minerales metálicos y no metálicos

0.09

Metálicas básicas

0.09

Fab. de muebles, colchones, persianas

0.09

Fuente: Elaboración propia. *El resto de las industrias no reportadas en la tabla presentaron una probabilidad nula de proximidad. 
La figura 12 muestra el espacio de subsectores exportadores en el nivel nacional ${ }^{5}$, donde cada nodo representa un subsector industrial exportador y su tamaño, el nivel del indicador betweeness centrality. En esta figura, se observa que aunque la industria del Equipo de Transporte es la que tiene la mayor participación en el nivel nacional en el sector exportador, de acuerdo con la tabla A2, son las Industrias de Alimentos y de Bebidas y Tabaco las que tienen el indicador de betweeness centrality más elevado, lo que sugiere un papel importante de estas en la conectividad con el resto de los sectores. También destacan las de Plástico y Hule, así como la de Química y Madera, como las de mayores enlaces hacia otras industrias.

Figura 12

\section{Total del país}

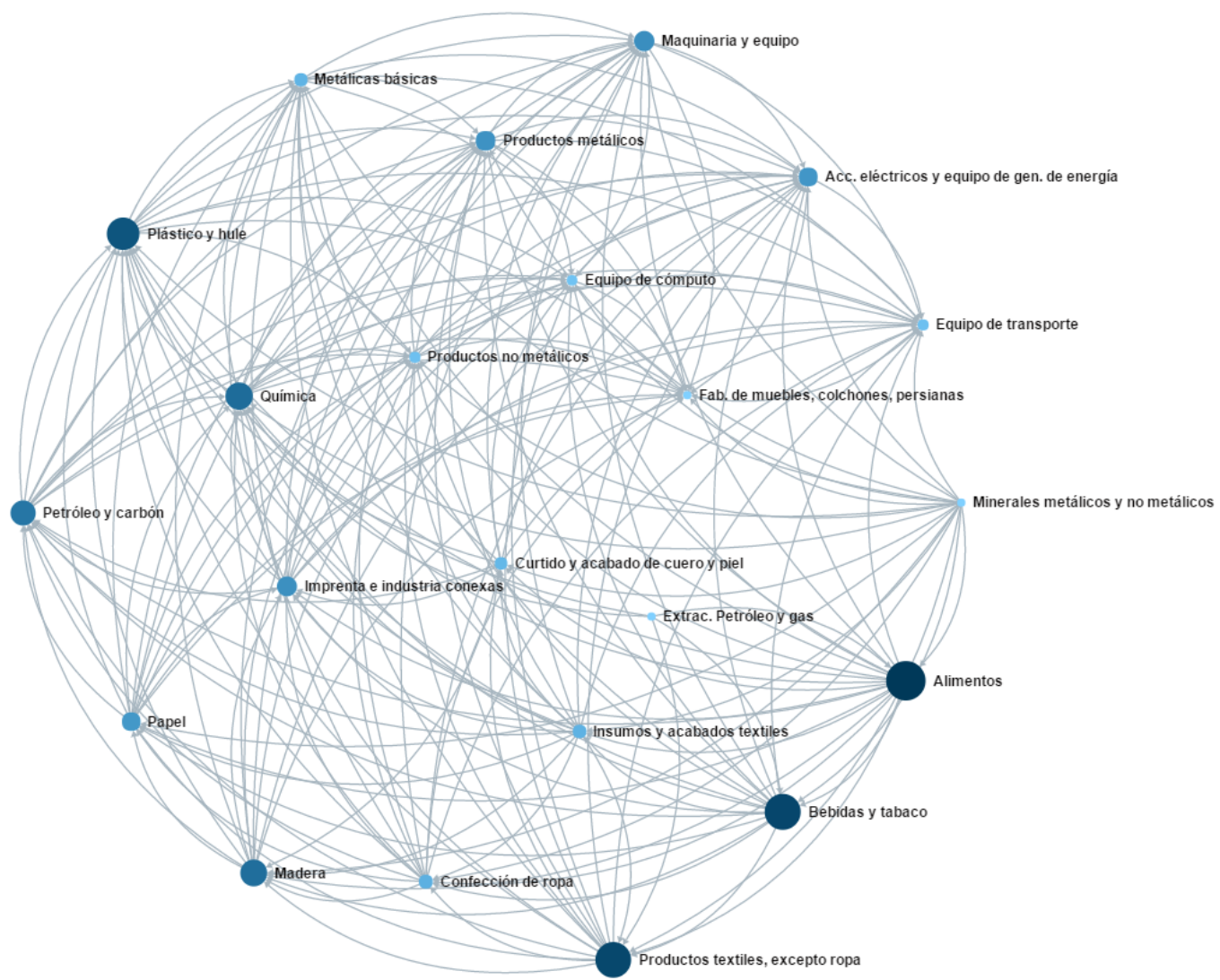

Fuente: Elaboración propia.

\footnotetext{
${ }^{5}$ Para la elaboración gráfica del análisis de redes se usó el paquete POLINODE.
} 
Analizando el espacio de subsectores industriales de exportación por regiones, los resultados para la región Frontera muestran una mayor conectividad en los subsectores de Fabricación de Maquinaria y Equipo, Fabricación de Equipo de Cómputo, y la Industria Química (figura 13). Esto significa, por ejemplo, que los insumos, las habilidades y las capacidades técnicas que posee la región de la Frontera, que son utilizadas en la industria exportadora de Equipo de Cómputo, son muy similares a las que usan las industrias de Fabricación de Muebles, Productos Metálicos, Madera, Imprenta, Papel y Plástico y Hule, por lo cual, también estas tienen ventaja comparativa. Las industrias que no están presentes en esta conectividad con la industria exportadora de Equipo de Cómputo, son: Alimentos, Bebidas, Productos No Metálicos y Metálicas Básicas. Esto podría significar que existe capacidad potencial de diversificación exportadora en esas industrias a partir de los conocimientos y capacidades prevalecientes en la región. Asimismo, para esta región, el subsector de Equipo de Cómputo es el que reporta el mayor indicador de centralidad, lo que implica la importancia de esta industria en la interactividad de la región.

La figura 14 muestra la respectiva red para la región Centro-Bajío y en la cual los subsectores de mayor participación exportadora son también Equipo de Transporte y Equipo de Cómputo. Las industrias con mayor grado de centralidad en esta red son: la de Productos Metálicos, Fabricación de Muebles, Imprenta e Industrias Conexas. Esto es, la industria de Productos Metálicos es la de mayor enlace hacia industrias como Química, Plástico y Hule, Insumos Textiles, Transporte, Alimentos e Imprenta, como las más sobresalientes. La conectividad de la Industria Exportadora de Muebles tiene también una relación cercana con casi todas las industrias, destacando Madera, Química, Metálicas Básicas y Papel. Las únicas industrias que no están presentes son la de Productos Minerales no Metálicos y los Derivados de Petróleo y Carbón. Lo anterior sugiere que el potencial de diversificación en las exportaciones de la región podría presentarse en la exportación de Minerales Metálicos y No Metálicos. 
172 Medellín, Flores y Villareal / Ensayos Revista de Economía, 36(2), 147-184

\section{Figura 13}

\section{Región Frontera}

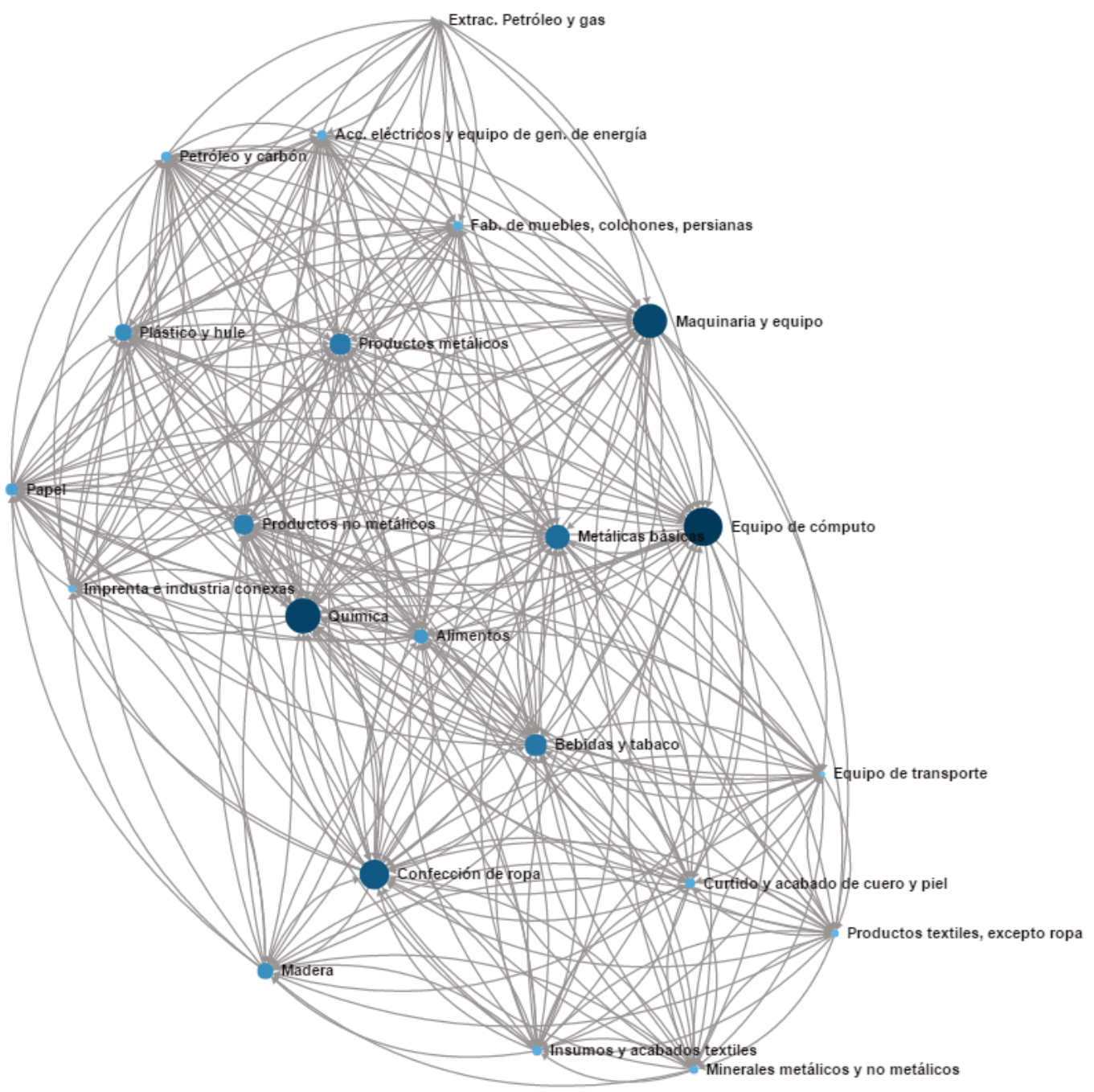

Fuente: Elaboración propia. 


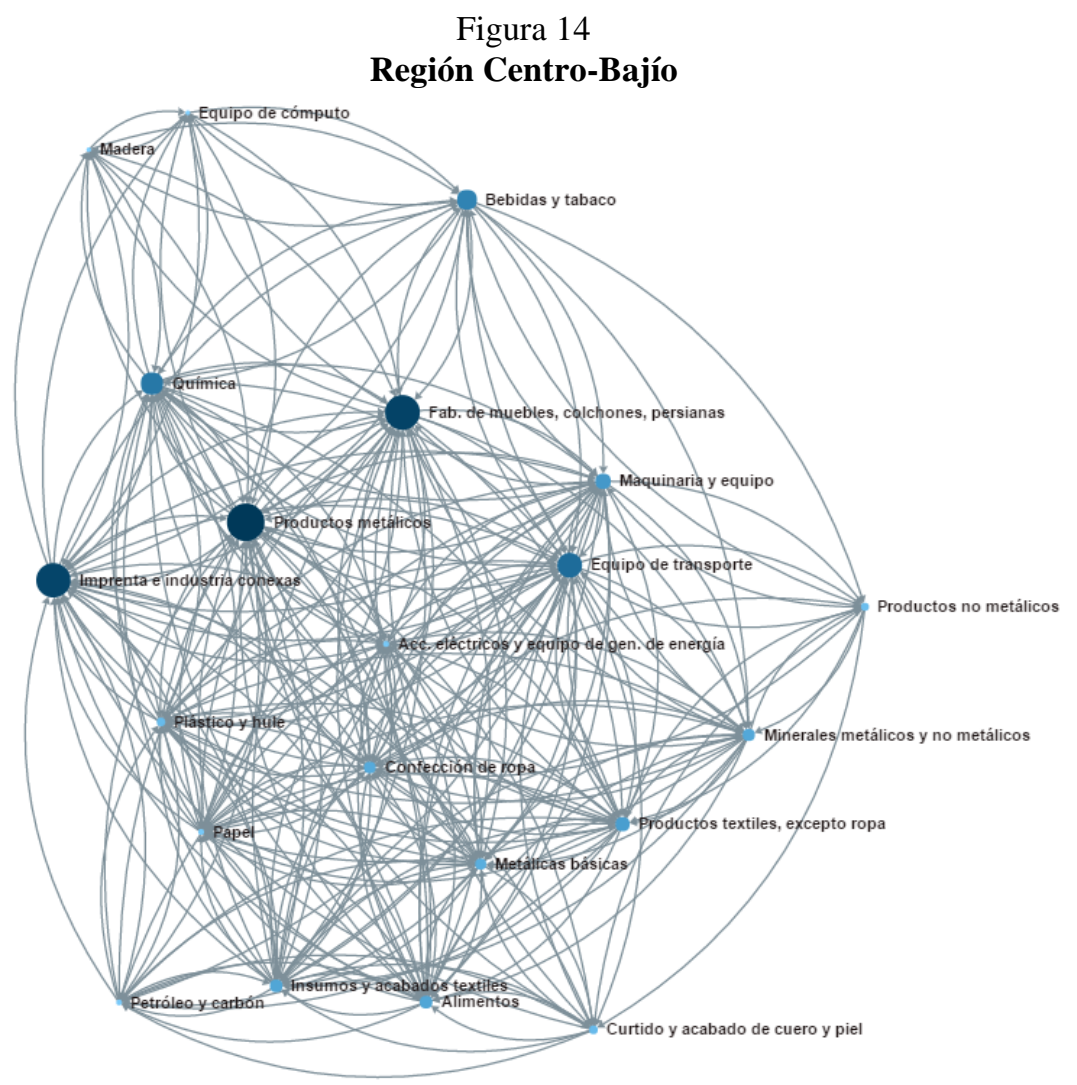

Fuente: Elaboración propia.

La conectividad de las industrias exportadoras en la región Centro-Capital (figura 15), están encabezadas por las industrias Metálicas Básicas, Maquinaria y Equipo y Curtido y Piel. La industria exportadora de Metálicas Básicas es la de mayores enlaces con industrias como Accesorios Eléctricos y Equipos de Generación Eléctrica, Maquinaria y Equipo, Química y Confección de Ropa. La única industria que no presenta interactividad con las Metálicas Básicas es la Industria de Equipo de Transporte, lo cual podría constituir un posible camino de diversificación en las exportaciones de la región, ofreciendo productos más sofisticados. Aun cuando la Industria de Equipo de Transporte es la que contribuye en mayor medida las exportaciones totales de la región, su nivel de centralidad es relativamente menor a la de Metálicas Básicas o de Maquinaria y Equipo. Al igual que en la región Centro-Bajío, la industria de Extracción de Petróleo y Gas no representa participación alguna en las exportaciones de la región, por lo que no está presente en este mapa regional. 


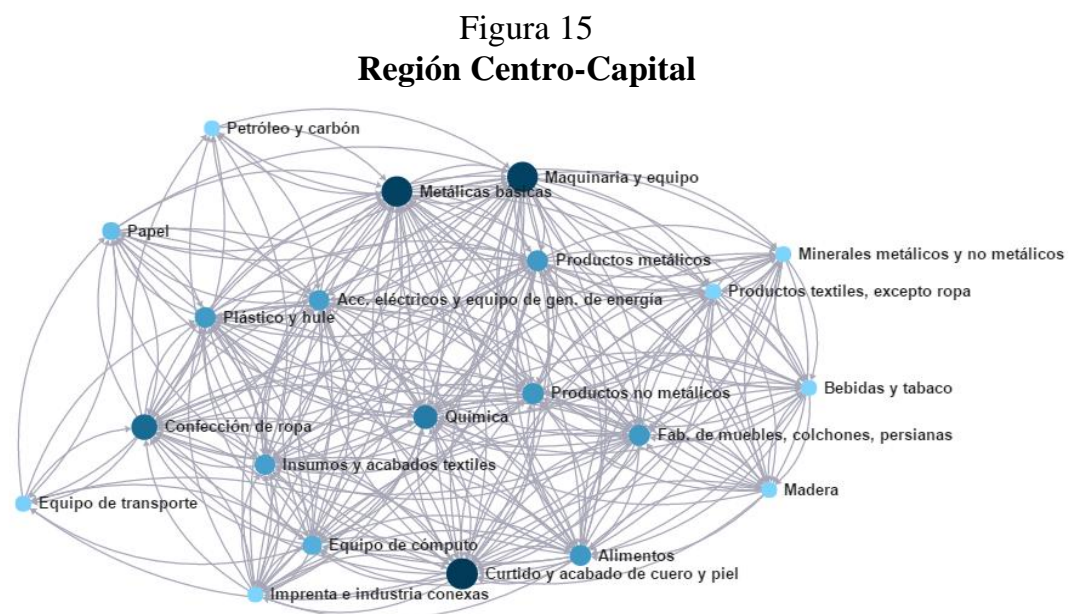

Fuente: Elaboración propia.

Para la región Sur, el subsector de Extracción de Petróleo y Gas tiene la participación más elevada y resulta poco conectado con el resto de los subsectores, pues solo tiene proximidad con la Industria de Plástico y Hule (figura 16). En esta región, es la industria de Plástico y Hule, la de mayor indicador de centralidad, le siguen la de Maquinaria y Equipo y la de Madera. La Industria de Plástico y Hule tiene la mayor conectividad con industrias como Alimentos, Bebidas, Productos Textiles y Productos Metálicos. La Industria de Minerales Metálicos y No Metálicos es la única que no presenta relación con la de Plástico y Hule. Igualmente, la Industria de la Madera, tiene enlaces con casi todos los sectores, excepto Curtido y Acabado de Cuero y Piel, Química, Imprenta, Metálicas Básicas, y Productos Metálicos, por lo que en estas industrias podría encontrarse el potencial exportador de la región Sur. Similar a lo encontrado por Chavez et al. (2015), en la región Sur predominan subsectores tradicionales en sus exportaciones, como Alimentos y Bebidas, con pocos productos de alta intensidad tecnológica, como Química, Equipo de Transporte y Equipo de Cómputo. 


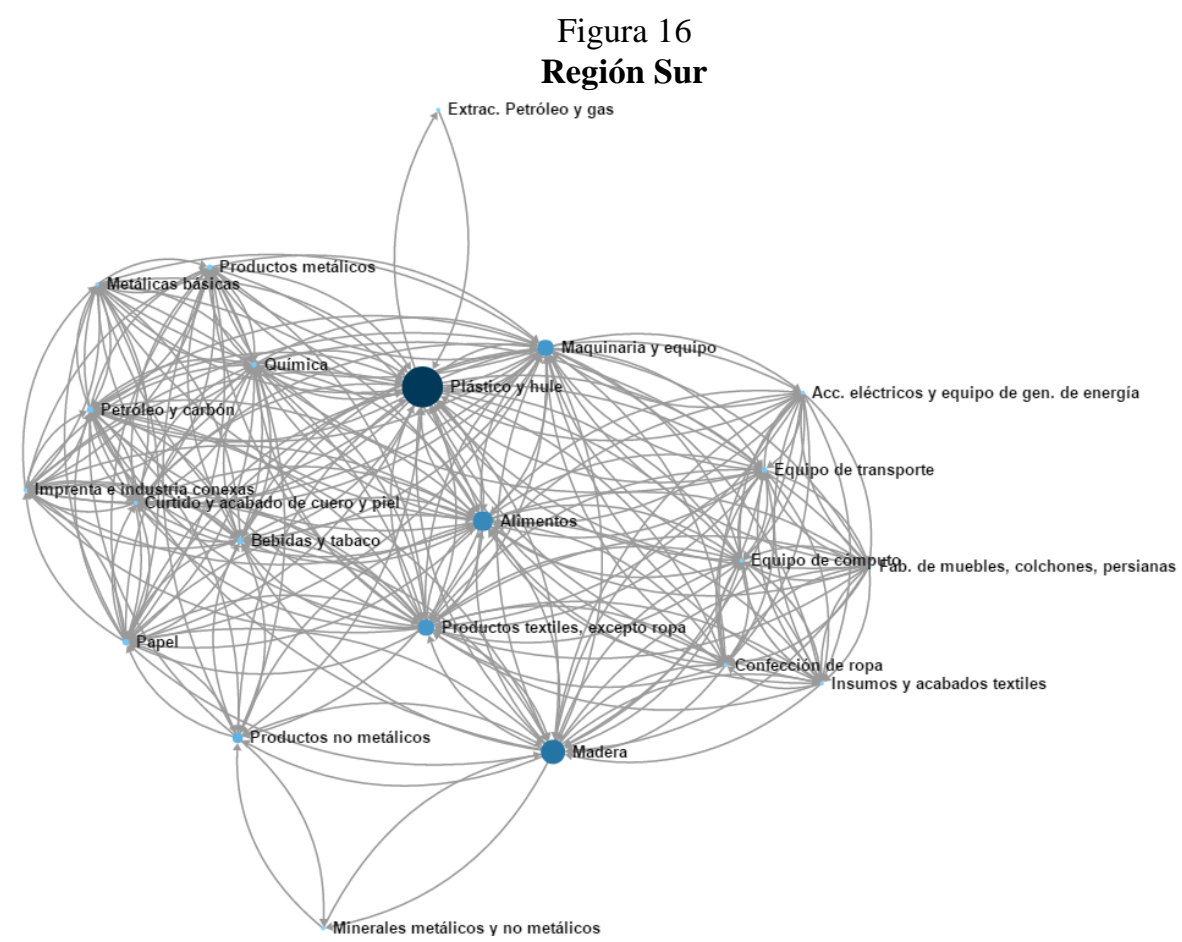

Fuente: Elaboración propia.

En la Tabla 4, se presenta, como comparativo final de las regiones, la estimación del indicador de centralidad ${ }^{6}$ para cada uno de los subsectores industriales por región. Comparando a nivel nacional con el resto de las regiones, se observa que la región Sur cuenta con menos subsectores con conectividad industrial exportadora, siendo la Industria de Plástico y Hule la de mayor interacción con el resto de los subsectores exportadores. Mientras que la región Frontera es la que presenta conectividad en casi todos los sectores, excepto uno, el de Extracción de Petróleo y Gas. De hecho, esta industria no resulta con interactividad en ninguna de las regiones. Además, en las regiones Frontera, Centro-Bajío y Centro-Capital, destacan los subsectores de mediana y alta intensidad tecnológica, como Maquinaria y Equipo, Equipo de Cómputo, Química, Productos Metálicos y Metálicas Básicas. Mientras que en el Sur, predominan las industrias de baja intensidad tecnológica como Plásticos, Alimentos, Bebidas y Madera, por mencionar algunas.

\footnotetext{
${ }^{6}$ Para la elaboración de estas medidas se usó el paquete de redes UCINET.
} 


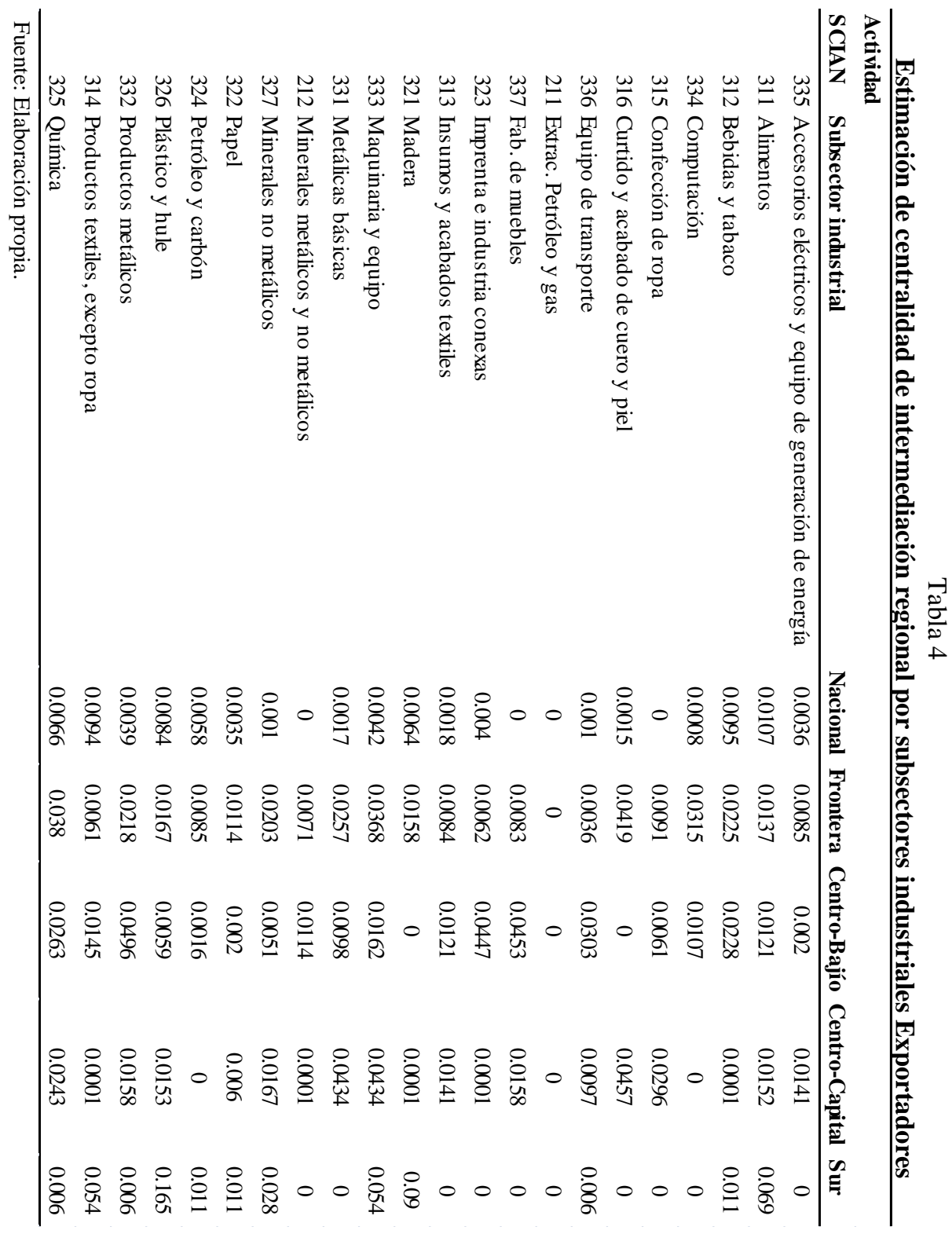


Resumiendo, las capacidades potenciales del sector exportador encontradas por región, aunadas con la centralidad de intermediación regional que se tienen estos sectores, pueden ser indicio de caminos para diversificación económica regional, que apoye al fortalecimiento en las cadenas productivas de la región. Así, por ejemplo, el potencial en la región Frontera de los sectores de Alimentos, Bebidas, Productos Minerales No Metálicos y Metálicas Básicas pueden ser puentes que apoyen a una mayor diversificación del sector exportador y se genere un mayor crecimiento económico local. Examinando el caso de la región Sur, donde se encuentran los estados en los que predominan sectores exportadores de baja intensidad tecnológica, puede encontrar su potencial exportador en industrias como Química, Minerales no Metálicos y Productos Metálicos, porque también tienen cierto grado de centralidad con el resto de los subsectores de la región. Estos resultados son similares al encontrado por Flores y Gómez (2017), quienes afirman que para las Zonas Económicas Especiales, determinadas por Chiapas, Guerrero, Michoacán, Veracruz y Oaxaca, las principales oportunidades de diversificación se encuentran en sectores como Minerales no Metálicos, Industria de Alimentos y Prendas de Vestir.

\section{Discusión final}

En este trabajo, se analiza la información de las exportaciones en el nivel de subsector industrial por entidad federativa, con el fin de estimar indicadores regionales de sofisticación, productividad y el espacio de subsectores industriales exportadores. En ese sentido, se encuentra que las industrias relacionadas con productos de media y baja intensidad tecnológica, como Bebidas y Tabaco, Fabricación de Madera, y los productos derivados del Petróleo y Carbón, tienden a tener un bajo nivel de PRODY, mientras que las relacionadas con el sector de alta intensidad tecnológica, como la de Extracción de Gas y Petróleo, Productos Metálicos, Química y de Fabricación de Aparatos Eléctricos destacan entre las industrias de más alto PRODY para el periodo de 2007 al 2013. En relación a la sofisticación de exportaciones señalada con el EXPY, los productos que han alcanzado un mayor crecimiento provienen, básicamente, de las industrias de Alimentos, Química, Productos No Metálicos, Metálicas Básicas, Maquinaria y Equipo, Transporte y Cómputo. San Luis Potosí, Sonora y Aguascalientes son las entidades que reportan un mayor crecimiento en el nivel de sofisticación de sus exportaciones, en ese lapso.

En este contexto de sofisticación de las exportaciones, se planteó ubicar los subsectores industriales que muestran una similitud o proximidad a partir de los conocimientos y capacidades requeridas y existentes, en los diferentes sectores exportadores en una región. Lo anterior se logra mediante la estimación regional de un espacio de subsectores industriales de exportación. 
Este espacio de subsectores industriales es visualizado, y sus propiedades exploradas, a través del análisis de redes o grafos. Así, se observa que las principales industrias exportadoras en las regiones analizadas, son: Equipo de Cómputo, Maquinaria y Química, para la región Frontera; la de Productos Metálicos, de Muebles e Imprenta, para la región Centro-Bajío; la Industria de Maquinaria y Equipo, Metálicas Básicas, Curtido y Acabado de Cuero y Piel, para la región Centro-Capital y para la región Sur, solamente Plástico y Madera. No obstante, en la región Frontera, se podría tener un potencial de diversificación de exportaciones relacionado con las industrias como Alimentos, Bebidas, Productos No Metálicos y Metálicas Básicas. Mientras que en la región Sur, el potencial podría ubicarse en las industrias que tienen una intensidad tecnológica mediana y alta, como Química, Metálicas Básicas y Productos Metálicos.

De este análisis, se desprende que una de las implicaciones de política pública en el nivel subnacional, consiste en diseñar estrategias que apoyen el desarrollo de cadenas productivas en sectores exportadores con mayor proximidad en el espacio de industrias, las anteriormente llamadas potenciales, ya que se podría impulsar una mayor complejidad económica del sector, generar mayor crecimiento económico regional y rehacer las cadenas productivas que se desvincularon con el proceso de liberalización comercial de los noventas. Por lo tanto, se vuelve imprescindible estimar formalmente el grado de interacción económica interregional del país, lo que hace necesaria una regionalización de la matriz insumo producto nacional; para, a partir de esto, generar escenarios de impacto y así dilucidar cuáles serían aquellas cadenas productivas con mayor efecto regional y, potencialmente, con el resto del país.

Adicionalmente, se observa que los subsectores de Minerales No Metálicos y Extracción de Petróleo y Gas muestran una reducida conectividad con el resto de subsectores en diferentes regiones, lo cual es una evidencia empírica de que la Reforma Energética podría detonar una mayor conectividad, potenciando una mayor complejidad económica y acelerando a su vez el crecimiento, en especial de la región Sur del país, que muestra los menores niveles de sofisticación industrial.

Cabe resaltar que el sector energético mantiene un buen número de empresas con capital y proveeduría extranjeros. Lo anterior muestra que cadenas productivas frágiles pueden verse afectadas por cambios en la política industrial o empresarial en los países de origen de estas industrias, lo cual hace vulnerable a nuestra planta productiva. En el ámbito de una política pública encaminada a fortalecer esta conectividad interindustrial, se presenta la necesidad de profundizar en un Plan de Desarrollo de Proveedores nacionales, enfocado en el sector energético, que en esencia realice las 
consecuentes actividades centrales para promover el contenido nacional y la consolidación de cadenas productivas estratégicas del país.

Por último, el presente análisis debe ser considerado como punto de partida para estudios ulteriores. Por ejemplo, es posible estimar un espacio de subsectores industriales en el nivel de área metropolitana, con lo cual se podrían identificar áreas geográficas específicas, donde la sofisticación de exportaciones y la conectividad industrial determinen un conglomerado local importante.

\section{Referencias}

[1] Aditya, A. y Acharyya, R. (2013). "Export diversification, composition, and economic growth: Evidence from cross-country analysis". The Journal of International Trade and Economic Development, 22(7), 959-992.

[2] Anand, R., Mishra S. y Spatafora, N.(2012)."Structural Transformation and Sophistication Production". International Monetary Fund.WP/12/59.

[3] Balassa, B. (1965). "Trade Liberalization and "Revealed" Comparative Advantage". The Manchester School of Economics and Social Studies, 33, 99123.

[4] Balassa, B. (1979). "The Changing pattern of Comparative Advantage in Manufactured Goods". The Review of Economics and Statistics, 61(2), 259266.

[5] INEGI. Banco de Información Económica. Instituto Nacional de Estadística, Geografía e Informática. Disponible en http://www.inegi.org.mx/sistemas/bie/

[6] Bonachev, D. y Buck, G. (2005). "Quantitative Measures of Network Complexity". En Bonachev D.,Rouvray D-H. (Eds.), Complexity in Chemistry, Biology and Ecology, (191-235).

[7] Boyandin, I., Bertini, E.y Lalanne, D.(2012). “A Quality Study on the Exploration of Temporal Changes in Flow Maps with Animation and Small-Multiples". Eurographics Conference on Visualization (EuroVis), 31(2), 1005-1014.

[8] Cadot, O., Carrere, C. y Strauss-Khan, V. (2013). “Trade Diversification, Income and Growth: What do we know?". Journal of Economic Surveys, 27(4), 790812.

[9] Chávez, J., Mosqueda, M. y Gómez-Zaldívar, M. (2015).“Economic Complexity and regional growth performance, evidence from the Mexican Economy". Banco de México.

[10] Dávila , A. (Coordinador).(2015).’Modelos Interregionales de Insumo Producto de la Economía Mexicana. Monterrey, N.L., México: MAPorrúa.

[11] Drew, R., Aggleton, P., Chalmers, H.y Wood, K. (2011). "Using social network analysis to evaluate a complex policy network".Evaluation, 17(4), 383-394.

[12] ECLAC (2012). "Structural Change for Equality. An Integrated Approach to Development". Economic Commission for Latin America and the Caribbean. Santiago de Chile:United Nations.

[13] Flores, M. y Gómez, F. (2017). "Urbanization in Latin America: Exclusion, Marginality and Conflict”. Latin America Division Conference 2017, São Paulo, Brazil. 
[14] Fisher, M. (2011). "Social network analysis and qualitative comparative analysis: Their mutual benefit for the explanation of policy network structures". Methodological Innovations Online, 6(2), 27-51.

[15] Freeman, L. (1977). "A set of measures of centrality based on betweenness". Sociometry, 40(1), 35-41.

[16] Freeman, L. (1979). "Centrality in Social Networks Conceptual Clarification". Social Networks, 1, 215-239.

[17] Hausmann, R., Hwang, J. y Rodrik, D. (2007) . "What You Export Matters". Journal of Economic Growth, 12(1),1-25.

[18] Hausmann, R., Hwang, J. y Rodrik, D. (2003) . "Economic development as selfdiscovery". Journal of Development Economic, Elsevier, 72(2),603-633.

[19] Hausmann, R. and Klinger, B.(2008). "Growth Diagnostic: Peru”. Inter-American Development Bank.

[20] Hausmann, R. y Klinger, B.(2006). "Structural Transformation and Pattern of Comparative Advantage in the Product Space". Center of International Development, Harvard University. Working Paper No.128.

[21] Hidalgo, C. y Hausmann, R. (2009). "The Building Blocks of Economic Complexity". Center for International Development and Harvard Kennedy School at Harvard University.

[22] Hidalgo C., Klinger B, Barabasi A-L, Hausmann, R. (2007). "The product space conditions the development of nations". Science, 317, 482-487

[23] Hernández, M., Soto, A., Vázquez, R. (2008). "Impacto Subregional del TLCAN.Sonora en el contexto de la frontera norte”. Frontera Norte. 20(40), 105-134.

[24] Herzer, D. y Nowak-Lehnmann, F. (2006). "What Does Export Diversification Do For Growth? An Econometric Analysis". Applied Economics, 38, 18251838.

[25] Jason, L. y Zhang, M. (2013). "Edge Betweeness Centrality". En Werner, D., Wolkenhauer, O., Kwang-Hyun, Ch., y Horoki, Y. (Ed), Encyclopedia of Systems Biology, Ecological Modeling, Springer.

[26] Mendoza, E. y Martínez, G. (1999). "Modelo de externalidades para el crecimiento manufacturero regional”. Estudios Económicos, 14(2), 231-263.

[27] Naudé, W., Bosker, M. y Matthee, M. (2010). "Export Specialization and Local Economic Growth". The World Economy. Blackwell Publishing Ltd.

[28] Newman, M.E.J. (2010). "Networks: An introduction". Hardback. Oxfor University Press. ISBN13:9780199206650, ISBN10:0199206651.

[29] Ramirez, Miguel D. (2003). "Mexico under NAFTA: a critical assessment". The Quarterly Review of Economics Finance, 43, 863-892.

[30] Santos-Paulino, A. (2011). "Trade specialization, export productivity and growth in Brazil, China, India, South Africa and a cross section of countries". Economic Change Restruct. 44,75-97.

[31] Trejo, A. (2008). "Disparidades regionales en el sector manufacturero. Problemas del Desarrollo". Revista Latinoamericana de Economía, 39(154), 88-109.

[32] Villarreal , A., Mack, E. A. y Flores, M. (2016). "Industrial Complexes in Mexico: Implications for Regional Industrial Policy Based on Related Variety and Smart Specialization". Regional Studies, DOI: 10.1080/00343404.2015.1114174.

[33] Wasserman, S. y Faust, K. (1994). "Social Network Analysis: Methods and Applications". Cambridge University Press. 


\section{Anexo}

Figura A1

Crecimiento medio anual de las exportaciones* (2007-2013)

$\begin{array}{lllllll}-5 \% & 0 \% & 5 \% & 10 \% & 15 \% & 20 \% & 25 \%\end{array}$

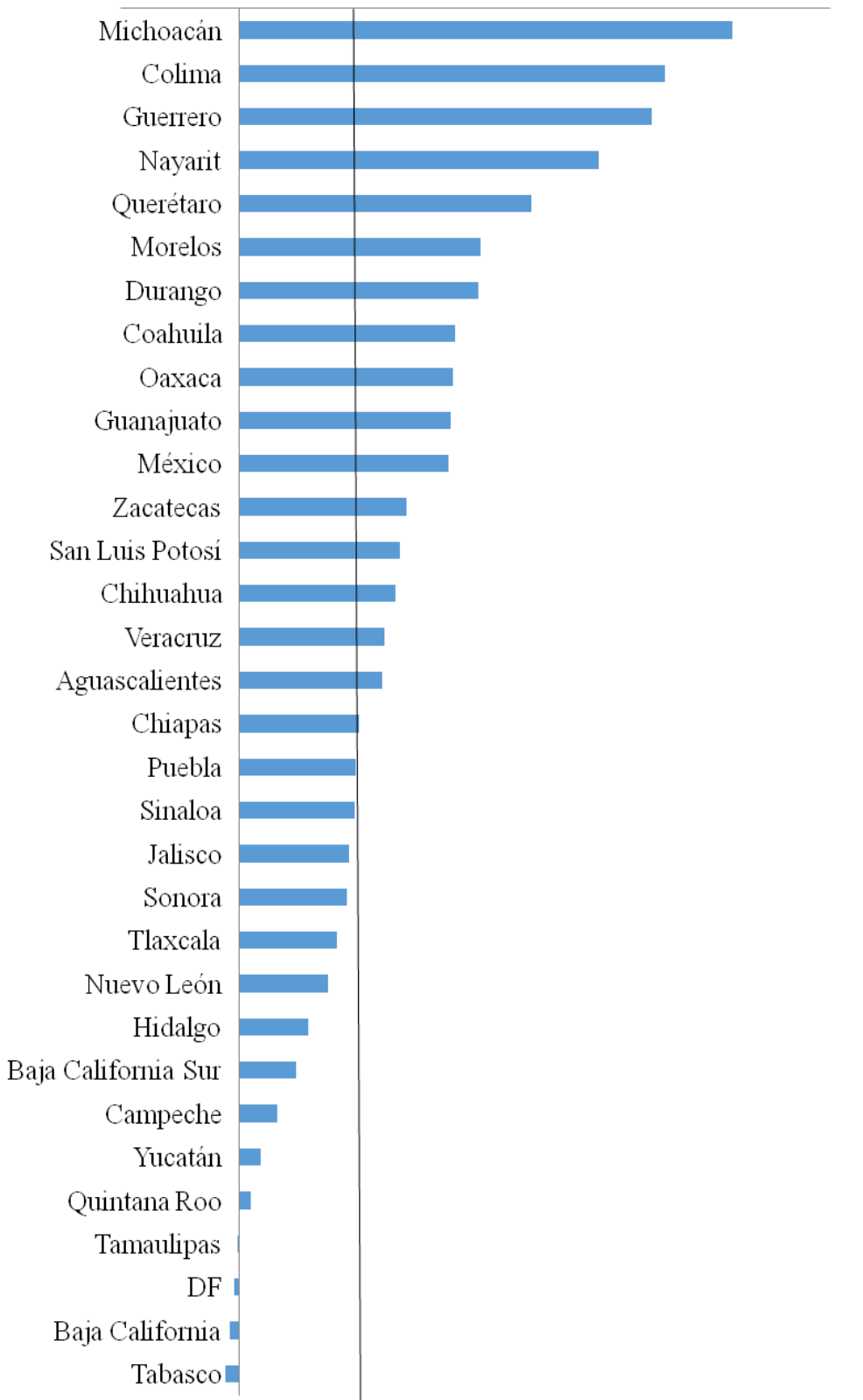

Fuente: Elaboración propia con datos de INEGI.* Las exportaciones sólo incluyen el sector minería y manufacturas. 


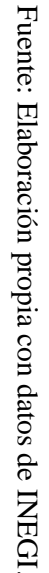

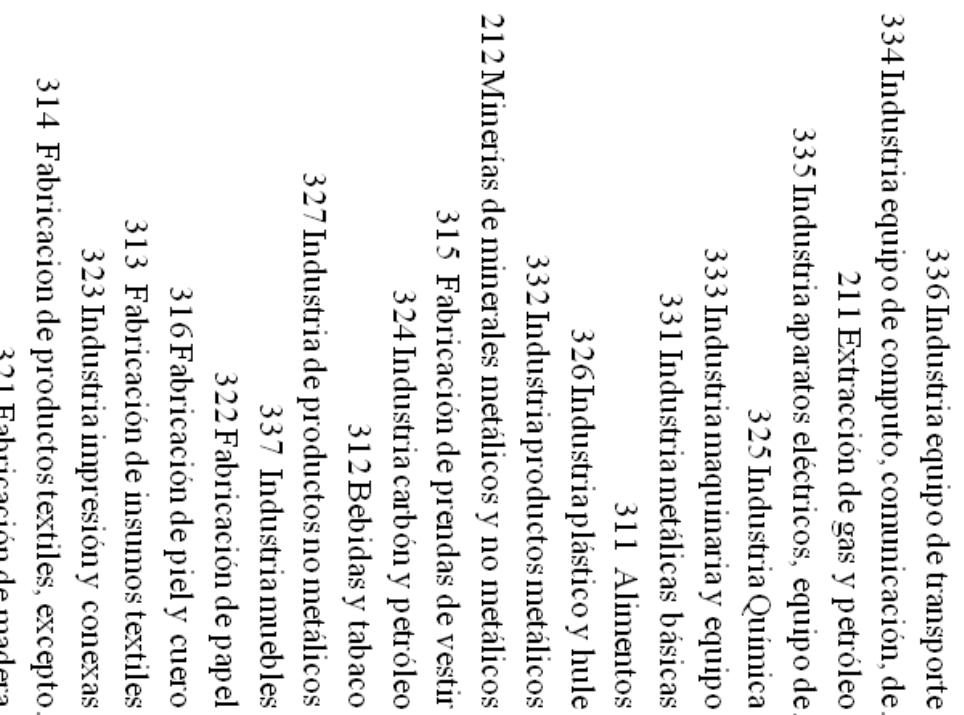

ڤั.

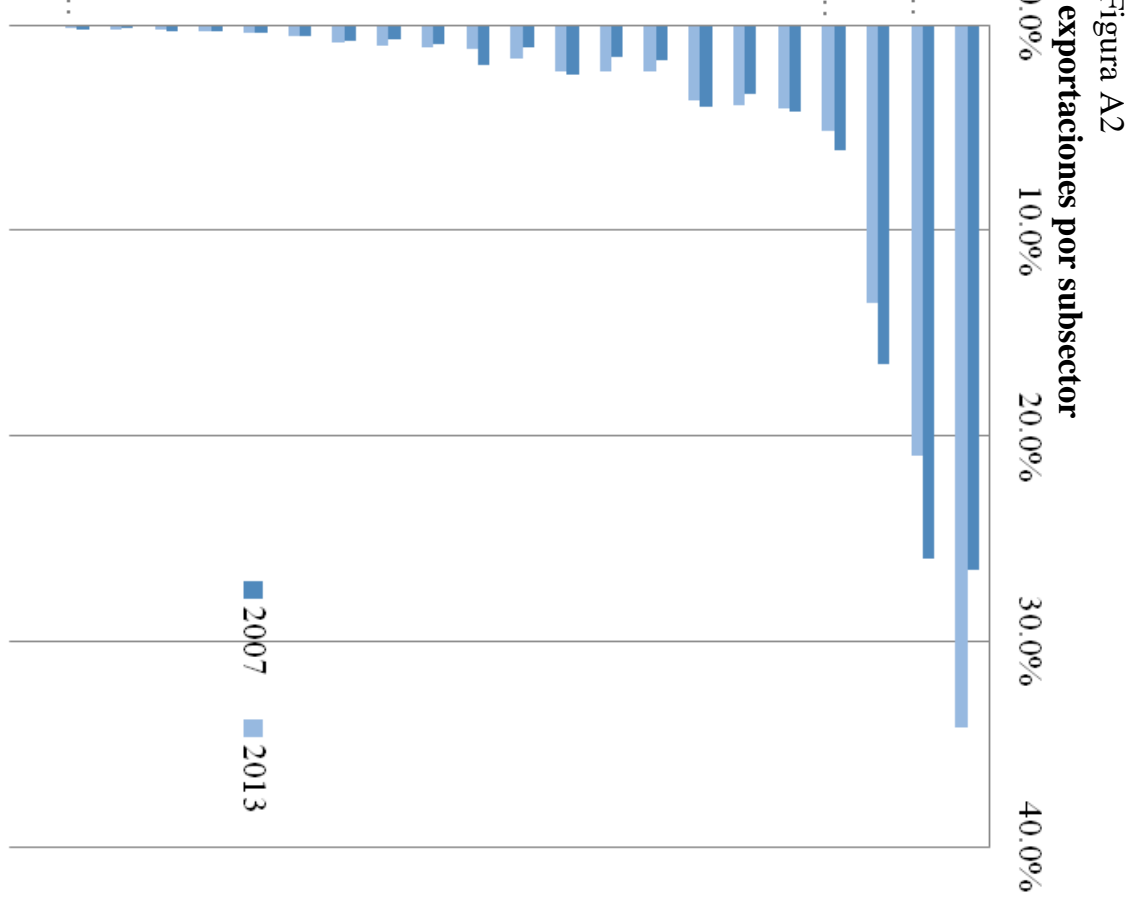


Medellín, Flores y Villareal / Ensayos Revista de Economía, 36(2), 147-184 183

Tabla A3

Estadística descriptiva de Indicador de EXPY (dólares)

\begin{tabular}{llcl}
\hline Año & Media & Min & Max \\
\hline 2007 & 11,819 & 5,036 & 36,336 \\
2008 & 12,206 & 5,699 & 37,906 \\
2009 & 9,084 & 4,018 & 22,602 \\
2010 & 10,440 & 4,483 & 26,828 \\
2011 & 11,402 & 5,233 & 32,343 \\
2012 & 11,456 & 5,540 & 31,318 \\
2013 & 11,631 & 5,783 & 29,536 \\
\hline
\end{tabular}

Fuente: Elaboración propia. 
184 Medellín, Flores y Villareal / Ensayos Revista de Economía, 36(2), 147-184 